\title{
Corrosion protection mechanisms of carbon nanotube and zinc-rich epoxy primers on carbon steel in simulated concrete pore solutions in the presence of chloride ions.
}

\author{
Y. Cubides, H. Castaneda* \\ ${ }^{a}$ Department of Materials Science and Engineering, Texas A\&M University, College Station, TX \\ 77843, USA \\ *Corresponding author: hcastaneda@tamu.edu, Phone: +1 9794589844 \\ Address: Reed McDonald building, 575 Ross Street, College Station, TX 77843, Office 230 \\ Y. Cubides: ypc2@tamu.edu
}

\begin{abstract}
This study investigates the electrochemical characterization of carbon nanotube and zincrich epoxy primers (CNT-ZRPs) on carbon steel in simulated concrete pore (SCP) solutions in the presence of chloride ions. The mechanistic performance of CNT-ZRPs was characterized by adding different zinc content. The electrochemical results indicated a dominant barrier protection effect for the coating with $60 \mathrm{wt} \% \mathrm{Zn}$ while there was a mixed corrosion protection mechanism for the coating with $70 \mathrm{wt} \% \mathrm{Zn}$ and a dominant cathodic protection mechanism for coatings with
\end{abstract}


higher zinc content ( $80 \mathrm{wt} \%$ and $90 \mathrm{wt} \% \mathrm{Zn}$ ). These barrier and cathodic protection control mechanisms were characterized quantitatively by electrochemical and high-resolution techniques.

\section{Introduction}

Reinforced concrete structures exhibit high corrosion resistance due to their highly alkaline conditions ( $\mathrm{pH}$ 12.5-13). Carbon steel can be used for rebar since it forms a passive oxide layer consisting of iron oxide $\left(\gamma-\mathrm{Fe}_{2} \mathrm{O}_{3}\right)$ and magnetite $\left(\mathrm{Fe}_{3} \mathrm{O}_{4}\right)$, which prevents and controls the corrosion-induced deterioration [1-5]. Economic advantages are also an important characteristic of ferrous alloys since they represent cost-effective solutions. Nevertheless, carbon steels are susceptible to halides in electrolyte solutions such as chloride ions, and these charge entities can influence the breakdown of the passive layer and the appearance of localized attack [5-8]. Following corrosion or activation processes, damage to concrete structures can be more severe when corrosion products induce high mechanical stresses that cause the formation of cracks in the concrete surface and even collapse of the structure $[9,10]$.

Several coating systems have been studied to control or mitigate rebar deterioration due to corrosion processes, including inorganic, organic, and hybrid protective coatings [11-15]. Zinc-rich epoxy primer (ZRP) has been applied since the 1930s due to its anti-corrosion properties [16]. These composite materials exhibit two protection mechanisms when an electrolyte penetrates into the organic binder. First, ZRPs provide cathodic protection by acting as sacrificial anodes when they are in electronic contact with the carbon steel surface [17]. Once cathodic protection is no longer active, ZRPs start to provide barrier protection due to the characteristic nature of the epoxy binder and the formation of zinc corrosion products on both the carbon steel surface and within the binder. These products fill in pores and reduce the amount of electrolyte that reaches the steel surface [18].

Nevertheless, it has been reported that high zinc content (> $90 \mathrm{wt} \%$ ) is not sufficient to ensure cathodic protection for a long time, especially for zinc particles with spherical geometry where there is only a single contact between two adjacent particles [19]. In such conditions, selfcorrosion of zinc particles due to the presence of oxygen and water will lead to rapid loss of the electrical connection among themselves and with the carbon steel surface [19]. In addition, a high amount of zinc particles can reduce the adhesion to the metal substrate and create 
difficulties in spraying due to high viscosity and poor dispersion [20]. Therefore, studies have been performed to develop ZRPs with high electrical conductivity but with lower amounts of zinc particles [21-23].

An attractive option for improving ZRP performance is associated with the presence of carbon nanotubes (CNTs) integrated within the binder. CNTs provide excellent mechanical and electrical properties, large surface area, high thermal stability, and chemical inertness [23-25]. CNTs can interconnect the zinc particles and provide higher electrical conductivity with which the percolation threshold can be reached with a lower zinc concentration compared with the traditional zinc-rich epoxy primer (90 wt\% Zn content) [23]. Counter effects in the coating performance have been reported due to the formation of microgalvanic cells between CNTs and metal compounds resulting in the acceleration of the oxygen reduction reaction [26]. Different works have also shown effective improvement in the corrosion protection of composite coatings using CNTs by distributing the electrical current to prevent localized attack in the metal surface. In addition, CNTs can provide barrier protection to composite coatings as pore fillers within the epoxy coating [27-29].

In this work, the influence of CNTs on the corrosion protection mechanism of CNT-ZRPs was evaluated in simulated concrete pore solution in the presence of chloride ions by electrochemical impedance spectroscopy (EIS). Coating systems were studied with a fixed amount of less than $1 \mathrm{wt} \%$ CNTs and four different zinc contents $(60 \mathrm{wt} \% \mathrm{Zn}, 70 \mathrm{wt} \% \mathrm{Zn}, 80$ $\mathrm{wt} \% \mathrm{Zn}$, and $90 \mathrm{wt} \% \mathrm{Zn}$ ). Evolution of the corrosion performance of these systems was also observed by localized electrochemical impedance spectroscopy (LEIS), scanning electron microscopy (SEM) coupled with energy dispersive X-ray spectroscopy (EDS), and X-ray photoelectron spectroscopy (XPS) to support the electrochemical mechanism findings.

\section{Experimental procedure}

\subsection{Electrolyte solution}

The electrolyte used simulates a concrete pore solution contaminated by chloride ions. Table 1 shows the chemical concentration of each of the species in this solution. Sodium chloride $(\mathrm{NaCl})$ was added to investigate the influence of chloride ions on the corrosion degradation process. All used chemicals were analytical grade and water was deionized with the highest purity. The resulting electrolyte had a chloride to hydroxide ratio of 1 that corresponds to 
a sodium chloride concentration of $0.1 \mathrm{M}$ and a $\mathrm{pH}$ of 12.87 . This chloride to hydroxide ratio $\left(\left[\mathrm{Cl}^{-}\right] /\left[\mathrm{OH}^{-}\right]\right)$was higher than the critical chloride concentration reported for concrete structures, which has been established as around 0.6 [30-32]. All testing procedures (except for localized electrochemical impedance spectroscopy) were performed by using concrete pore solution.

The solution was selected based on previously studies [33-38]. It is important to clarify that this solution does not include all chemical species contained in real cement concrete pore solutions such as fly ash, silica fume, gypsum, etc. However, sodium hydroxide $(\mathrm{NaOH})$, potassium hydroxide $(\mathrm{KOH})$, and calcium hydroxide $\left(\mathrm{Ca}(\mathrm{OH})_{2}\right)$ represent the chemistry of the concrete in a controlled environment and the electronic properties of the passive film formed at the steel surface used as the reinforced material [38].

\subsection{Coating samples}

Carbon nanotubes and zinc-rich epoxy primers were provided by Tesla NanoCoatings company. The coating formulation corresponds to a solvent-based two component epoxypolyamide primer that incorporates sacrificial zinc particles in spherical configuration together with carbon nanotubes. To prepare the zinc-rich coating formulations, epoxy resin (Tesla P1150ASAS) was mechanically mixed with a fixed composition of $<1 \mathrm{wt} \%$ of carbon nanotubes (CNT). After CNTs were completely dissolved in the epoxy resin, different weight percentages of zinc particles were added gradually to the mixture while stirring at room temperature. Finally, a stoichiometric amount of hardener (Tesla P1150BSAS) with a weight ratio (epoxy resin: hardener) of 2:1, was added to the mixture and sonicated for $5 \mathrm{~min}$. The different coating formulations are listed in Table 2. The prepared coatings were air sprayed on AISI 1008 carbon steel (UNS G10080) with a chemical composition (maximum nominal composition in wt\%) of $0.60 \% \mathrm{Mn}, 0.15 \% \mathrm{C}, 0.030 \% \mathrm{P}, 0.035 \% \mathrm{~S}$ and balance Fe. The dimensions of the substrate panels were $152 \times 76 \times 1 \mathrm{~mm}$. Prior to the application of coatings, steel panels were sandblasted followed by degreasing with acetone and drying at room temperature. The coating systems were allowed to cure for 6 hours at $60{ }^{\circ} \mathrm{C}$ and then, they were kept at room temperature for seven days before exposure to the electrolyte solution. Samples were exposed by using a glass tube fixed on the coating surface by an O-ring and a metal clamp that exposed a surface area of $4.67 \mathrm{~cm}^{2}$. The dry film thickness was measured by an Elcometer 456 coating thickness gauge. 


\subsection{Electrochemical measurements}

Electrochemical measurements were conducted using a Biologic SP-200 Research Grade Potentiostat/Galvanostat/FRA. A conventional three-electrode cell was used at room temperature. The coated samples served as the working electrodes, a saturated calomel electrode (SCE) was used as the reference electrode, and $\mathrm{Pt} / \mathrm{Nb}$ mesh electrode of $2 \mathrm{~cm}$ diameter was the counter electrode. The electrochemical testing procedure included measurements of open circuit potential (OCP) and electrochemical impedance spectroscopy (EIS) during 150 days. Open circuit potential was measured for 10 minutes following impedance measurements in a frequency range of $100 \mathrm{kHz}$ to $10 \mathrm{mHz}$ at 6 points/decade with $10 \mathrm{mV}$ amplitude. All electrochemical impedance spectroscopy measurements were performed at the open circuit potential. The impedance results were fitted with equivalent electrical circuits using the Z Fit tool of the EC-lab software. All electrochemical tests were performed in duplicate to guarantee reproducibility of the OCP and EIS measurements.

\subsection{Local electrochemical impedance spectroscopy (LEIS)}

LEIS measurements were performed to study the cathodic protection properties of CNTZRPs. An artificial defect of $4 \mathrm{~mm} \times 1 \mathrm{~mm}$ was made on a coated sample of $1 \mathrm{~cm}^{2}$, which was then electrically connected using a conductive silver paint to a metal sample embedded in epoxy resin. The edges of the coated sample were isolated with silicone glue and then, it was allowed to dry for one day. This setup was required due to the configuration of the VersaSCAN L-Cell. The LEIS measurements were performed on a VersaSTAT 3F Potentiostat coupled to a VersaSCAN electrometer and controlled by VersaSCAN software.

A five-electrode cell was used with a saturated calomel electrode as the reference electrode, a platinum wire as the counter electrode, the coated sample as the working electrode, and a LEIS probe as a dual-element probe that scans the local impedance in a defined surface area. A $0.005 \mathrm{M} \mathrm{NaCl}$ solution was used to guarantee low electrical conductivity that ensure accuracy of the LEIS results [39, 40]. The size of the scanned area (length $\mathrm{x}$ width) was $6.75 \mathrm{x} 4$ $\mathrm{mm}$. The LEIS measurements were carried out with a potential amplitude of $10 \mathrm{mV}(\mathrm{rms})$ and at a single frequency of $10 \mathrm{~Hz}$. 


\subsection{Morphology characterization}

Damage evolution processes for the different carbon nanotubes and zinc-rich epoxy primers were characterized by SEM coupled to EDS. Coated samples with a $1 \mathrm{~cm}^{2}$ surface area were immersed in a simulated concrete pore solution with $\left[\mathrm{Cl}^{-}\right] /\left[\mathrm{OH}^{-}\right]$ratio of 1 . The samples were removed following immersion for 5, 20, 50, and 90 days. For the cross-section images, the exposed coated samples were embedded in epoxy resin and cut perpendicular to the exposed area. The epoxy resin was used to reduce the modification or damage of the coated samples during the cutting process. Samples were rapidly dried with air and then maintained in a desiccator to avoid additional degradation on the carbon steel surface. The cross section and surface morphologies of the samples were examined before and after immersion with a HITACHI® TM3000 Tabletop Microscope SEM. Elemental content in the different samples was determined by EDS.

\subsection{X-ray photoelectron spectroscopy (XPS)}

The surface chemical compositions of the coated samples were analysed by X-ray photoelectron spectroscopy (XPS) on an Omicron XPS/UPS system with an Argus detector using a $\mathrm{Mg} \mathrm{K} \alpha$ X-ray source $(1253.6 \mathrm{eV})$. The spectrometer was equipped with an electron flood source (CN 10 scientaomicron) to provide charge neutralization to the coated samples and an argon ion sputter gun (NGI3000 LK Technologies) for surface cleaning. The hemispherical analyser was operated in a fixed analyser transmission (FAT) mode with a pass energy of $100 \mathrm{eV}$ for the survey spectra and $20 \mathrm{eV}$ for the high-resolution spectra. Binding energies for XPS spectra were calibrated with reference to the $\mathrm{C} 1 \mathrm{~s}$ adventitious carbon peak $(285 \mathrm{eV})$. Identification of chemical species in high-resolution spectra was defined based on literature data.

CasaXPS software was used for peak fitting and quantification of atomic compositions by using a Gaussian-Lorentzian procedure and a Shirley type for the background subtraction. For the peak fitting of the high-resolution spectra, position constraints were added based on reported literature values, and the equality of full-width at half-maximum (FWHM) of a peak was considered for all peaks within each core level.

\section{Results and discussion}

\subsection{Open circuit potential (OCP)}


For reinforced concrete structures, the potential criterion for cathodic protection has been bounded with minimum and maximum values. Some authors have reported a maximum value of $-720 \mathrm{mV}$ vs. $\mathrm{Ag} / \mathrm{AgCl} / 0.5 \mathrm{M} \mathrm{KCl}(-0.763 \mathrm{~V}$ vs. SCE), which represents the potential at which cathodic protection is no longer effective [41, 42]. In addition, a minimum value of $-1100 \mathrm{mV}$ vs. $\mathrm{Ag} / \mathrm{AgCl} / 0.5 \mathrm{M} \mathrm{KCl}(-1.143 \mathrm{~V}$ vs. SCE) has been reported in association with a hydrogen evolution process [41, 42]. Fig. 1 shows the evolution of the open circuit potential (OCP) for CNT-ZRPs at different zinc contents immersed in the simulated concrete pore solution for 150 days. Fig. 1 shows that OCP values for carbon nanotube and zinc-rich epoxy primer with $60 \mathrm{wt} \%$ Zn (CNT-60ZRP) were more positive than the cathodic protection limit, which means that no sacrificial protection was provided to the metal substrate. Following the protection mechanism of CNT-60ZRP, the OCP magnitudes suggest a barrier-type corrosion protection to the carbon steel surface in which the zinc particles are mostly isolated by the epoxy matrix.

In contrast, the OCP values for carbon nanotube and zinc-rich epoxy primer with $70 \mathrm{wt} \%$ $\mathrm{Zn}$ (CNT-70ZRP) were located in the cathodic protection region during the first five days of immersion, suggesting the presence of cathodic protection and/or zinc dissolution processes. Following five days of immersion, OCP values for CNT-70ZRP shifted rapidly to a more positive magnitude and reached a value close to $-0.02 \mathrm{~V}$ vs. SCE, which remained constant until the end of the immersion test. To investigate the influence of CNTs in the zinc-rich epoxy primer, OCP values for zinc-rich epoxy primer with $70 \mathrm{wt} \%$ zinc and without the presence of carbon nanotubes are also reported. Fig. 1 shows that the potential values for this formulation lie above the cathodic protection region. These results indicate that CNTs improved the electronic connection between the zinc particles allowing to provide cathodic protection to the metallic substrate during the first days of immersion.

Carbon nanotube and zinc-rich epoxy primers with $80 \mathrm{wt} \% \mathrm{Zn}$ and $90 \mathrm{wt} \% \mathrm{Zn}$ (CNT80ZRP and CNT-90ZRP) also exhibited OCP values within the cathodic protection region that remained for longer immersion time. Formulations with higher zinc concentration provided higher galvanic function due to the zinc content and CNTs that can help to improve the electronic contact between the zinc particles and the carbon steel surface. For CNT-80ZRP, the potential decreased rapidly during the first days of immersion due to electrochemical reactions between the zinc particles and the electrolyte. Abreu et al. [43] defined this period as an activation period in which native zinc oxide reacts with chloride ions and increases the zinc 
active area, leading to better electronic connection between the zinc particles and the carbon steel surface.

Importantly, between three and seven days of immersion when zinc particles were mostly activated by the electrolyte, the OCP values were more negative than the magnitude for cathodic protection. This suggests that hydrogen reduction was feasible at the metal substrate. After seven days of immersion, the OCP increased into the cathodic protection region, leading to suppression of the hydrogen evolution reaction and the presence of zinc corrosion processes in conjunction with the oxygen reduction reaction. In the same period, the zinc-to-iron area ratio decreased due to the zinc dissolution. Finally, the potential shifted to values above the cathodic protection region and had almost constant magnitude for the rest of the exposure time. This might indicate the presence of a protective layer that isolates the carbon steel surface from the aggressive environment.

For sample CNT-90ZRP, the OCP also decreased below the cathodic protection threshold. As mentioned, this behaviour is associated with the hydrogen reduction reaction and available active sites. However, unlike CNT-80ZRP, the potential was below the minimum limit on only the second day of immersion and then shifted to the cathodic protection region. In addition, cathodic protection persisted for a longer time compared to CNT-80ZRP due to the higher amount of electronic pathways that interconnect the zinc particles with the carbon steel surface.

\subsection{Electrochemical impedance spectroscopy (EIS)}

\subsubsection{CNT-60ZRP}

Fig. 2 shows the impedance spectra for CNT-60ZRP at different immersion times. This formulation exhibited almost capacitive behaviour during the entire immersion test with high impedance values at $0.01 \mathrm{~Hz}\left(10^{9}-10^{10} \mathrm{ohm}-\mathrm{cm}^{2}\right)$, which means that good barrier protection was provided by the coating system and charge transfer processes did not occur on the carbon steel substrate. This behaviour can be attributed to the presence of the epoxy binder with relatively low porosity where zinc particles were highly wetted by the epoxy resin. The anticorrosive properties of these coatings can also be attributed to the presence of CNTs, which can fill in micropores and flaws inside the epoxy binder [27, 28]. Additionally, Jeon et al. [27] reported that CNTs act as adhesion promoters between the epoxy coating and the carbon steel surface, leading to higher resistance to coating delamination and blister formation. 


\subsubsection{CNT-70ZRP}

The impedance spectra for the CNT-70ZRP sample are shown in Fig. 3. These results show capacitive behaviour at the initial time. Following resistive behaviour after the first day of immersion. One possible explanation can be associated to an increase in the porosity of the epoxy binder due to the higher amount of zinc particles. Thus, it could be possible that there were not enough CNTs to fill in the majority of pores and therefore, water uptake was observed after a few days of immersion.

Based on the impedance spectra, we identified three different stages during the entire immersion test. As an initial stage, water uptake took place inside the epoxy binder. The Nyquist curve showed only one capacitive loop, and the Bode plot exhibited high impedance magnitudes at $0.01 \mathrm{~Hz}$ (around $1 \times 10^{8} \mathrm{ohm}-\mathrm{cm}^{2}$ ) that were close to the values reported for organic coatings that provide only barrier protection [44]. Marchebois et al. [45] attributed this capacitive loop in zinc rich epoxy primers with the respective zinc content to a mixed impedance response considering the barrier effect of the epoxy binder, contact impedances between the zinc particles due to the presence of zinc oxide that electrically insulates the zinc particles, and electrochemical reactions taking place at the zinc particles surface (zinc oxidation and oxygen reduction reaction). They also reported that at the beginning of the immersion time, the influence of the zinc particles in the impedance response was dominated by contact impedances, but the faradaic processes at the zinc particles became more relevant after several days of immersion [45].

In the second stage, a second time constant (or loop in the Nyquist representation) can be distinguished at low frequency after 20 days of exposure. This behaviour can be explained by the presence of charge transfer processes (zinc dissolution) at the surface of the zinc particles and/or at the metal substrate interface. This is in agreement with the mechanism reported by Marchebois et al. [39]. Finally, a third stage can be identified following 100 days of immersion. The second time constant at low frequency disappeared, and a straight line emerges in the complex representation. This behaviour has been associated with a mass transfer mechanism as the control-dominant process within the zinc corrosion products located at the carbon steel surface [45].

\subsection{3. $C N T-80 Z R P$}


Fig. 4 shows the impedance spectra for CNT-80ZRP. Following the first day of immersion, the Bode plot (Fig. 4b) shows a step-down change in the impedance magnitude at the lowest frequency $(0.01 \mathrm{~Hz})$, with a significant decrease between $10^{3}$ and $10^{4} \mathrm{ohm} \mathrm{cm}^{2}$. This behaviour can be associated with a capillary transport mechanism due to high porosity of the coating, which enables high galvanic influence by the zinc particles [46]. However, following 10 days of immersion, the impedance magnitude at $0.01 \mathrm{~Hz}$ started to increase due to presence of zinc corrosion products that were formed during the cathodic protection mechanism. This trend was observed during the remaining immersion time, which may indicate that a stable zinc oxide/zinc hydroxide layer was formed.

The corrosion degradation mechanism for this formulation was defined in terms of four stages. In the first stage, the complex representation (Fig. 4a) produces one semicircle during the first three days of immersion. This can be associated with the mentioned mixed impedance response in which, dielectric properties of the binder, contact impedances, and activation of the zinc particles contribute to the global impedance response.

In the second stage, after five days of immersion, there was a noticeable change in the Nyquist representation (Fig. 4a) due to the appearance of two capacitive loops from high to medium frequencies and an inductive loop at the lowest frequencies. This trend was not observed in previous studies on zinc-rich epoxy primers in seawater or $3.5 \mathrm{wt} \% \mathrm{NaCl}$ solutions [11, 4648]. However, during this exposure time, the OCP evolution shows that hydrogen reduction reaction could have occurred at the carbon steel surface due to the highly alkaline environment. Therefore, a mechanism involving the hydrogen evolution should be considered.

Alonso et al. [49] studied the risk of hydrogen embrittlement in galvanized reinforcing steel exposed to alkaline solutions. They reported that between $\mathrm{pH} 12.5$ and 13.5, zinc oxidation takes place in the presence of hydrogen evolution according to the following reaction:

$\mathrm{Zn}+2 \mathrm{H}_{2} \mathrm{O} \rightarrow \mathrm{Zn}(\mathrm{OH})_{2}+\mathrm{H}_{2}(\mathrm{~g}) \uparrow$

where the hydrogen evolution proceeds in the following sequence of reactions:

$$
\begin{aligned}
& \mathrm{H}^{+}+\mathrm{e}^{-} \rightarrow \mathrm{H}_{\mathrm{ad}} \\
& \mathrm{H}_{\mathrm{ad}}+\mathrm{H}_{\mathrm{ad}} \rightarrow \mathrm{H}_{2}(\mathrm{~g}) \uparrow
\end{aligned}
$$

From this mechanism, it can be suggested that the capacitive loop at the highest frequencies represents the dielectric properties of the epoxy binder, the capacitive loop observed from high to medium frequencies describes the zinc dissolution process accompanied by the 
hydrogen reduction reaction (reaction 1), and the inductive loop at the lowest frequencies can be associated with adsorption of hydrogen in the metallic substrate (reaction 2). Based on the OCP results, hydrogen evolution reaction was observed for seven days of immersion, and then, the potential increased above of the threshold magnitude into the cathodic protection region. This behaviour agrees with the signal change in the Nyquist representation for 10 days of exposure, where the inductive loop disappeared and another capacitive loop started to develop at the highest frequencies.

This behaviour represents the third stage in the corrosion degradation mechanism of this coating system. Cathodic protection was active in this stage, meaning that zinc dissolution occurred on the zinc particle surfaces while oxygen reduction reaction took place at the carbon steel surface. In addition to the capacitive loops representing the barrier properties of the coating, and the galvanic function provided by the zinc particles, the capacitive loop that started to develop at the highest frequency was related to the formation of a layer of zinc corrosion products due to the cathodic protection process.

In the fourth stage, two semicircles were observed at medium to high frequencies with one large semicircle at the lowest frequency following 20 days of exposure, when cathodic protection was no longer effective. As mentioned, the semicircle at the highest frequency was associated with the formation of a protective layer that provided an extra barrier to subsequent permeation of oxygen and ionic species. This semicircle increased over time, which could be related to continued growth of the protective layer. The loop at middle frequencies represents the barrier properties of the coating, which also increased over time due to the protective layer of zinc corrosion products that it was primarily formed at the coating-electrolyte interface. Finally, the third time constant at low frequency was related to a self-corrosion process of the zinc particles that were not involved in the cathodic protection process. In this process, both zinc dissolution and oxygen reduction reaction occurred on the zinc particle surfaces.

\subsubsection{CNT-90ZRP}

Fig. 5 shows the impedance results for CNT-90ZRP at different exposure times in the simulated concrete pore solution. The evolution of the impedance spectrum for CNT-90ZRP was similar to that of the CNT-80ZRP sample. Nevertheless, we noticed several differences from the 
previous formulation that are worth mentioning. We could not detect an activation period (First stage of the corrosion degradation mechanism for CNT-80ZRP) in which resistance of the epoxy binder and contact impedances were dominant. This can be attributed to the excessive porosity of the epoxy binder due to high amount of zinc particles, which allowed for instant penetration of water and therefore, faster activation of the zinc particles that probably occurred within the first few hours after immersion.

The impedance signal associated with the hydrogen evolution reaction was only observed during the second day of immersion (i.e., the capacitive loops from high to medium frequencies and the inductive loop at the lowest frequencies). This is also in agreement with the OCP values in which the open circuit potential was below the minimum value for cathodic protection during only the second day of exposure. This means that the interruption of the hydrogen evolution reaction was faster compared to the sample containing $80 \mathrm{wt} \%$ zinc. Additionally, the cathodic protection period (third stage of the corrosion degradation mechanism for CNT-80ZRP) remained for longer time compared to the previous coating, which is expected due to higher amount of zinc particles in the epoxy binder. This higher zinc content increases the likelihood of forming more electronic pathways, either by direct contact between zinc particles or interconnection of zinc particles with carbon steel surface by the CNTs. The impedance response in the fourth stage, showing three capacitive loops that correspond to the protective layer of zinc corrosion products, barrier properties of the epoxy binder, and electrochemical reactions on the zinc particle surfaces, were also observed for CNT-90ZRP, indicating that the predominant corrosion protection mechanism corresponds to cathodic protection provided to the metallic substrate.

\subsubsection{Electrical equivalent circuit analysis}

Fig. 6 shows the electrical equivalent circuits used for impedance fittings of the CNT60ZRP and CNT-70ZRP samples. The equivalent circuit that represents the water uptake initiation was used to fit the impedance results for CNT-60ZRP during the entire exposure time. $R_{e}$ represents the electrolyte resistance between the reference electrode and the coated samples, and $\mathrm{C}_{\mathrm{c}}$ and $\mathrm{R}_{\mathrm{c}}$ describe the capacitance and pore resistance of the epoxy coating. For CNT70ZRP, the three equivalent circuits were used to interpret the different stages that were identified from the impedance response. Here, $C_{c}$ and $R_{c}$ describe the dielectric properties of the 
epoxy binder and also the contribution of contact impedances between the zinc particles. $\mathrm{C}_{\mathrm{dl}}$ and $\mathrm{R}_{\mathrm{ct}}$ shown in stages II and III represent the double layer capacitance and the charge transfer resistance at the interface between the zinc particles and the electrolyte. W in stage III corresponds to the Warburg impedance describing a mass transfer-controlled process. For all equivalent circuits, constant phase elements (CPEs) were used instead of capacitances due to surface heterogeneities, deviation from capacitive behaviour, and dispersion effects. The impedance for a $\mathrm{CPE}$ is defined as:

$\mathrm{Z}_{\mathrm{CPE}}=\frac{1}{\mathrm{Y}_{0}(\mathrm{j} \omega)^{\mathrm{n}}}$

where $Y_{0}$ and $n$ represent the admittance and empirical exponent of the constant phase element, $j$ is the imaginary number, and $\omega$ is the angle frequency.

Fig. 7 shows the evolution of the different equivalent circuit elements for CNT-60ZRP and CNT-70ZRP. Fig. 7a shows high coating resistance $\left(\mathrm{R}_{c}\right)$ values for CNT-60ZRP close to $10^{10} \mathrm{ohm} \mathrm{cm}^{2}$, with no significant change in its magnitude during the entire exposure time. In addition, it can be also notice that the $\mathrm{Y}_{\mathrm{o}, \mathrm{c}}$ values for the CNT-60ZRP sample did not change considerably during the complete immersion time. Since the magnitudes of $R_{c}$ and $Y_{o, c}$ are related to the coating porosity and the diffusion of electrolyte inside the coating [44, 50], these results suggest that the CNT-60ZRP system remained almost intact during the entire immersion time.

In contrast, changes in $R_{c}$ and $Y_{o, c}$ were observed for CNT-70ZRP. Fig. 7b shows that during 100 days of exposure, $R_{c}$ decreased and $Y_{o, c}$ slightly increased due to water penetration. After this time, both parameters remained almost constant due to formation of zinc corrosion products that slowed down the additional permeation of water and ionic species. $\mathrm{Y}_{\mathrm{o}, \mathrm{c}}$ values for CNT-70ZRP were considerably higher than the corresponding values for CNT-60ZRP. This latter was expected since higher amount of zinc particles in CNT-70ZRP leads to higher porosity in the epoxy matrix and therefore, higher diffusion of electrolyte within the coating system which increases its dielectric constant (directly proportional to the coating capacitance). Fig. 7b also shows the evolution of charge transfer resistance and double layer capacitance in CNT70ZRP. $\mathrm{R}_{\mathrm{ct}}$ decreased exponentially due to cathodic protection or dissolution processes provided by zinc particles. In contrast, $\mathrm{C}_{\mathrm{dl}}$ increased due to removal of native zinc oxide, which increases the active area of zinc that is available for the zinc dissolution processes. 
Fig. 8 shows the equivalent circuits proposed for CNT-80ZRP and CNT-90ZRP. The equivalent circuit in stage I describes the activation period of zinc particles. $R_{s}$ represents the electrolyte resistance, while $C_{c}$ and $R_{c}$ describe the capacitance and the resistance of the epoxy binder including contact impedances due to presence of native zinc oxide on the zinc particle surfaces. $\mathrm{C}_{1}$ and $\mathrm{R}_{1}$ represent faradaic processes between zinc particles and ionic species. The equivalent circuit in stage II describes the cathodic protection process in presence of hydrogen evolution reaction associated with adsorption of hydrogen on the metal substrate. $C_{2}$ and $R_{2}$ represent the zinc dissolution process in presence of hydrogen reduction reaction, and $L$ and $R_{L}$ describe the inductance and the resistance associated with the adsorption process of hydrogen on the carbon steel surface. The cathodic protection mechanism involving zinc dissolution in the presence of oxygen reduction reaction can be described by the equivalent circuit shown in stage III, where $\mathrm{C}_{3}$ and $\mathrm{R}_{3}$ are associated with the electrochemical process of zinc dissolution on the zinc particle surfaces and oxygen reduction on the carbon steel surface. $\mathrm{C}_{\mathrm{ox}}$ and $\mathrm{R}_{\mathrm{ox}}$ are related to the formation of zinc corrosion products on the coating/electrolyte interface. Finally, the equivalent circuit in stage IV represents the barrier protection period in which a layer of zinc corrosion products was formed at the top of the coating surface and cathodic protection was no longer active. This leads to zinc dissolution processes in the presence of oxygen reduction reaction both taking place on the zinc particle surfaces.

Fig. 9 shows the evolution of different equivalent circuit elements for CNT-80ZRP and CNT-90ZRP after the fitting procedure using the equivalent circuits in Fig. 8. $\mathrm{R}_{\mathrm{ct}}$ and $\mathrm{Y}_{\mathrm{o}, \mathrm{dl}}$ correspond to the values for the different charge transfer processes shown in Fig. 8; i.e., $\mathrm{C}_{1}$ and $R_{1}$ for stage $I, C_{2}$ and $R_{2}$ for stage II, $C_{3}$ and $R_{3}$ for stage III, and $C_{4}$ and $R_{4}$ for stage IV. Fig. 9a shows resistances and CPE values for CNT-80ZRP. These results show that $\mathrm{R}_{c}$ decreased during the activation stage (first stage) and during the hydrogen evolution process (second stage). This trend was expected since rapid diffusion of electrolyte within the coating influences the activation of zinc particles (due to dissolution of native zinc oxide by the electrolyte) which increases the electronic conductivity within the epoxy coating. $\mathrm{R}_{\mathrm{ct}}$ also decreased due to faradaic processes between zinc particles and ionic species that increase the zinc-to-steel area ratio, which means that more zinc active area was created for the cathodic protection process.

During this cathodic protection process, $\mathrm{R}_{\mathrm{c}}$ increased drastically due to formation of zinc corrosion products on the coating surface that prevent additional permeation of electrolyte. $\mathrm{R}_{\mathrm{ct}}$ 
also increased due to loss of electronic connection between the zinc particles, which decreases the galvanic function provided by the zinc particles in direct contact with them and with the carbon steel surface. During the last stage in which zinc particles no longer provide cathodic protection, $R_{c t}, R_{c}$, and $R_{o x}$ remained almost constant due to formation of a layer of zinc corrosion products on the coating surface, which slowed down the corrosion degradation process. Regarding the CPE values, both $\mathrm{Y}_{\mathrm{o}, \mathrm{c}}$ and $\mathrm{Y}_{\mathrm{o}, \mathrm{dl}}$ were considerably higher than the values reported for CNT-60ZRP and CNT-70ZRP. These results can be explained due to higher diffusion of electrolyte, which significantly increases the dielectric constant of the material. Also, higher zinc content provide more activation area for charge transfer processes.

Similar behaviour was observed for CNT-90ZRP, as shown in Fig. 9b. Nevertheless, it can be seen that cathodic protection period was extended compared to CNT-80ZRP sample due to the higher amount of zinc particles. In addition, unlike the $\mathrm{R}_{\mathrm{ct}}$ evolution for CNT-80ZRP, the $\mathrm{R}_{\mathrm{ct}}$ values for CNT-90ZRP increased during the last stage while the cathodic protection process was no longer active. This behaviour can be explained by the higher influence of self-corrosion processes of the zinc particles in the presence of oxygen reduction reaction taking place on the surface of the zinc particles.

Impedance magnitudes at $0.01 \mathrm{~Hz}$ are used to compare the differences between the CNTZRP systems and the result of this comparison are shown in Fig. 10. Three noticeable electrochemical behaviours are observed: A pure barrier protection mechanism (CNT-60ZRP), a mixed corrosion protection mechanism (CNT-70ZRP), and a cathodic protection mechanism (CNT-80ZRP and CNT-90ZRP).

The impedance signal for CNT-60ZRP describes a pure barrier protection, where the impedance magnitude at $0.01 \mathrm{~Hz}$ exhibited high values during the entire exposure time. The impedance behaviour can be explained by the low porosity of the epoxy binder and the influence of the CNTs as pore fillers.

There is no predominant mechanism for CNT-70ZRP and a mixed corrosion protection is observed. The mixed response is attributed to the presence of: a) barrier protection provided by the epoxy binder, and b) cathodic protection (or self-dissolution of zinc) provided by the zinc particles. The impedance magnitude at $0.01 \mathrm{~Hz}$ decreased during 100 days of immersion due to diffusion of electrolyte and zinc particle dissolution, which explains the barrier protection mechanism. After 100 days of immersion, the impedance magnitude remained constant due to 
the presence of zinc corrosion products in the epoxy coating, which explains the contribution of the cathodic protection process. In Fig.10, the impedance magnitude results for CNT-free 70ZRP are also reported along with the results for CNT-70ZRP; these values in absence of CNTs were significantly lower than when CNTs were added. This behaviour suggests that CNTs improved the overall anticorrosive performance of the zinc rich-epoxy primer.

The impedance response for CNT-80ZRP and CNT-90ZRP describes a predominant cathodic protection mechanism caused by the high concentration of zinc particles embedded in the epoxy. The low impedance magnitudes observed during the first few days of immersion are caused by the high galvanic action produced by the elevated concentration of zinc particles which, also induce the formation of a protective layer that provided extra protection to the carbon steel surface, manifested in a subsequent increase in the impedance magnitude. CNT-90 ZRP exhibited lower impedance magnitudes at $0.01 \mathrm{~Hz}$ compared to CNT-80ZRP due to higher amount of zinc particles that increases the porosity of the epoxy coating leading to higher electrolyte uptake. Additionally, higher amount of zinc particles increases the electronic conductivity of the coating system that facilitate charge transfer processes between them and with the carbon steel surface. These findings could be related to results reported by Shreepathi et al. [51], who studied the influence of zinc content on corrosion protection mechanisms of zincrich epoxy coatings in $3.5 \% \mathrm{NaCl}$. They found that coatings with $40 \mathrm{wt} \% \mathrm{Zn}$ provide excellent barrier protection, while coatings with $80 \mathrm{wt} \% \mathrm{Zn}$ and $90 \mathrm{wt} \% \mathrm{Zn}$ offer sacrificial protection. In addition, they also reported that intermediate zinc contents (60 wt $\% \mathrm{Zn}$ and $70 \mathrm{wt} \% \mathrm{Zn}$ ) did not provide clear evidence of dominance by one of these specific control actions.

\subsection{Local electrochemical impedance spectroscopy (LEIS)}

Since cathodic protection was provided by CNT-80ZRP and CNT-90ZRP, localized electrochemical impedance spectroscopy measurements were performed on a scratched CNT90ZRP sample to investigate the electrochemical performance of the coating sample when a damage is induced and the carbon steel surface is completely exposed to a $0.005 \mathrm{M} \mathrm{NaCl}$ solution. Fig. 11a shows the LEIS spectra for CNT-90ZRP at different immersion times. Fig. 11a shows that the local impedance spectra in the scratched area was slightly lower than in the coated areas in the first five hours of exposure. An iron dissolution process was associated with this behaviour since red spots were found after the exposure time. However, the local impedance in 
the damaged area was higher compared to the intact areas after 10 hours of exposure. This can be explained by the cathodic protection provided by the zinc particles in the epoxy binder in which zinc dissolution occurs on the intact coating, while oxygen reduction reaction occurs in the scratched area.

It is important to notice that the zinc particles integrated in the epoxy included a zinc oxide layer; therefore, the activation of the zinc particles was slower than the dissolution of the steel. Once the zinc particles are activated and providing cathodic protection, the prior steel dissolution cannot be reverted. This is the reason why, while the zinc particles were providing cathodic protection to the carbon steel surface after 10 hour of immersion, iron corrosion products were still found on the scratched area. However, it is also important to know that the extent of iron corrosion products on the defect was considerably lower than that of the zinc corrosion products.

Finally, after 35 hours of immersion, the local impedance between the intact and damaged areas were similar to each other. This means that zinc corrosion products were formed on the scratched area, which prevents subsequent dissolution of the carbon steel surface. Optical and 3D images (Fig. 11b) show these zinc corrosion products, which provided a temporary blockage for further corrosion degradation processes on the carbon steel surface.

\subsection{SEM and EDS analysis}

Fig. 12 shows cross-section and surface-view SEM images for CNT-60ZRP before and after immersion for 90 days in the electrolyte solution. The cross-section images (Fig. 12a and Fig. 12b) show that there was no significant change of the coating system during 90 days of exposure. This indicates that CNT-60ZRP provided a dominant barrier corrosion protection. It is evident from the images that there was no attack on the carbon steel surface. Fig. 12c shows the coating surface of CNT-60ZRP after 90 days of exposure. The coating surface showed the presence of precipitates. EDS analysis was performed in region 1, and the results are reported in Table 3. The results show that this region contains mostly oxygen and calcium, which means that calcium hydroxide $\left(\mathrm{Ca}(\mathrm{OH})_{2}\right)$ was precipitated from the simulated concrete pore solution. No sign of zinc corrosion products

was detected, proving that zinc particles were completely isolated by the epoxy resin. 
Fig. 13 shows morphology images of CNT-70ZRP and CNT-free 70ZRP at different immersion times. Fig. 13a shows the cross-section image of the intact CNT-70ZRP in which it can be noticed that zinc particles were not in direct contact with each other. After 5 days of immersion (Fig. 13b), the zinc oxide was removed from the surface of the zinc particles due to interaction with the electrolyte, which means that activation of the zinc particles occurred during this immersion period. Following 90 days of immersion, the cross-section image (Fig. 13c) shows that zinc corrosion products accumulated in the epoxy binder and at the carbon steel surface.

Table 3 shows the elemental composition of regions 1 and 2 in Fig. 13c. Zinc and oxygen were the primary elements in these regions, suggesting that zinc oxides/hydroxides were formed from electrochemical reactions between the zinc particles and the electrolyte (cathodic protection and self-corrosion processes). These electrochemical reactions explain the appearance of a time constant in the phase angle representation or a second loop from the complex representation following 20 days of immersion. The zinc corrosion products on the carbon steel surface were responsible for the diffusion-controlled process observed in stage III and the stabilization of the impedance magnitude (at $0.01 \mathrm{~Hz}$ ) after 100 days of immersion.

The coating surface image (Fig. 13d) following 90 days of immersion shows that zinc corrosion products were also formed at the coating surface. Table 3 shows their atomic composition, which was mainly oxygen and zinc. This also suggests the formation of zinc oxide/zinc hydroxide corrosion products. No iron corrosion products were observed at the carbon steel surface following 90 days of exposure. Therefore, from electrochemical and morphology analysis, it can be concluded that CNT-70ZRP has an efficient balance between physical barrier and cathodic protection.

SEM images are also reported for CNT-free 70ZRP. Fig. 13e shows the coating surface after 90 days of exposure. The EDS results in Table 3 show that region 1 corresponds only to precipitates of calcium hydroxide, but there is no evidence of zinc corrosion products. Fig. 13f shows the cross-section image for this formulation after 90 days of immersion. Zinc corrosion products were not found, but there was a high amount of iron corrosion products at the carbon steel surface. Table 3 reveals the elemental composition of region 2 and shows high atomic composition of iron and oxygen. These results demonstrate that CNTs had a positive effect on the anticorrosive performance of zinc-rich epoxy primers since they could improve the barrier 
properties of the epoxy binder. They could also enhance the electrical conductivity in the epoxy coating and allow the zinc particles to provide sacrificial action to the metallic substrate.

SEM images for CNT-80ZRP are observed in Fig. 14. The intact coating image (Fig. 14a) shows higher accumulation of zinc particles in the epoxy binder compared to the previous formulations. Importantly, even though there was a higher amount of zinc particles, some of them were not in direct contact with each other. This suggests that there was a limited electrical connection between the zinc particles and the carbon steel surface. Fig. 14b shows that large regions with empty spaces were created in the epoxy binder following 20 days of immersion. This behaviour can be explained by the cathodic protection process in which zinc dissolution takes place at the zinc particle surfaces while hydrogen evolution or oxygen reduction reaction occur at the metal substrate.

In addition, it can be noticed the presence of a layer of zinc corrosion products formed at the coating surface. Abreu et al. [46] reported that this layer is formed as a consequence of the galvanic corrosion process in which the $\mathrm{OH}^{-}$ions produced at the carbon steel surface due to reduction reaction and $\mathrm{Zn}^{2+}$ ions from zinc dissolution diffuse to balance the total charge in the epoxy coating. They then precipitate and form a barrier layer of zinc corrosion products at the coating/electrolyte interface.

CNTs could improve the effectiveness of the cathodic protection process by increasing the electrical contact between the zinc particles and the metal substrate. During the exposure time, the layer of zinc corrosion products became thicker. Following 90 days of immersion (Fig. $14 \mathrm{c}$ ), the layer reached an average thickness of $20 \mu \mathrm{m}$. In addition to the barrier layer at the coating surface, zinc corrosion products were also formed on the zinc particle surfaces. This indicates self-corrosion processes of the zinc particles that were not involved in the galvanic function.

The top-view image of CNT-80ZRP exposed for 90 days (Fig. 14d) shows that the coating surface was completely covered by zinc corrosion products. Table 3 shows atomic compositions of different morphologies identified from SEM images after 90 days of exposure. These results show that region 1 was enriched with zinc while region 2 was balanced between zinc and oxygen. This demonstrates the self-dissolution process of the zinc particles in the presence of oxygen reduction reaction, which induces the formation of zinc corrosion products at 
the surface of the zinc particles. Additionally, different $\mathrm{Zn} / \mathrm{O}$ ratios were found in regions 3, 4, and 5, suggesting that the barrier layer was a combination of zinc corrosion products.

As mentioned, the corrosion process for CNT-90ZRP was similar to the one for CNT80ZRP. This is in agreement with the evolution in SEM images (not shown here). Cross-section and surface coating micrographs showed almost the same morphology at different exposure times.

\subsection{XPS analysis}

XPS analysis was performed to identify the elemental and chemical composition at the coating surface for different formulations before and after immersion in the simulated concrete pore solution. The results indicate the presence of zinc corrosion products at the coating surface and their corresponding chemical nature. The survey spectrum provided a qualitative description of the elements at the coating surface. The corresponding high-resolution spectra for $\mathrm{Zn} 2 \mathrm{p} 3 / 2, \mathrm{C}$ 1s, and $\mathrm{O} 1 \mathrm{~s}$ allowed for identification of the chemical states and quantification of their compositions.

Fig. 15 shows the XPS spectra for CNT-60ZRP before and after immersion. The survey spectrum (Fig. 15a) shows the presence of oxygen, carbon, and nitrogen for both the intact and the exposed samples. No zinc was found, which is in agreement with the SEM results. Fig. 15b shows the $\mathrm{C} 1 \mathrm{~s}$ core level photoemission spectrum of CNT-60ZRP before immersion. The peak at the binding energy of $285 \mathrm{eV}$ was attributed to $\mathrm{C}-\mathrm{C} / \mathrm{C}-\mathrm{H}$ bonds, the contribution at $286.5 \mathrm{eV}$ was assigned to $\mathrm{C}-\mathrm{O} / \mathrm{C}-\mathrm{N}$ bonds, and the peak at $287.91 \mathrm{eV}$ was associated with $\mathrm{C}=\mathrm{O}$ bonds [5255]. The corresponding peaks for $\mathrm{C}-\mathrm{O}$ and $\mathrm{C}=\mathrm{O}$ bonds were also detected in the $\mathrm{O} 1$ s core level (not shown here) at $533.34 \mathrm{eV}$ and $534.77 \mathrm{eV}$, respectively [55-57]. These functional groups and their corresponding atomic compositions (Table 4) describe the presence of a conventional epoxy coating.

Fig. 15c shows the core level spectrum for C 1s after 90 days of exposure. Significant change was observed in the atomic composition of the outermost layer of the epoxy binder. In addition to the functional groups identified for the intact coating, a new peak was recognized at $288.8 \mathrm{eV}$ in the $\mathrm{C} 1 \mathrm{~s}$ core level attributed to carboxyl groups [54]. Table 4 shows a high increase in the atomic composition of $\mathrm{C}-\mathrm{O}$ groups. This behaviour can be explained by strong hydrogen 
bonding interactions between the water molecules and certain hydroxyl and amine groups of the epoxy polymer [58].

Mijovic et al. [59] reported that a water molecule can form hydrogen bonds with hydroxyl, ether, and tertiary amines of the epoxy network. It can also form hydrogen bonds between water molecules previously bound to the polymer, leading to the formation of dimers, trimers, or even water clusters. EIS measurements showed excellent charge transfer resistance and SEM images did not show significant degradation in the epoxy binder. However, the surface of the epoxy coating was highly altered by the direct contact with the electrolyte. This behaviour is in agreement with results by Li et al. [58], who reported that water binds with the hydrophilic groups of the epoxy polymer before diffusing into the free volume of micropores of the epoxy matrix.

XPS spectra are also reported for CNT-70ZRP. The survey spectra (Fig. 16a) show that the surface of the intact coating consisted predominantly of $\mathrm{C}, \mathrm{O}$, and $\mathrm{N}$. The coating exposed for 90 days to the electrolyte solution showed the presence of $\mathrm{Zn}, \mathrm{O}$, and $\mathrm{C}$, which is expected due to the formation of zinc corrosion products at the coating surface observed in SEM images. Notably, chloride ions were not found at the film surface, which is also in accordance with the EDS results in Table 3. This behaviour can be explained by the alkaline $\mathrm{pH}$ of the simulated concrete pore solution. In these conditions, zinc corrosion products containing chlorine such as simonkolleite $\left(\mathrm{Zn}_{5}(\mathrm{OH})_{8} \mathrm{Cl}_{2}\right)$ or zinc chloride $\left(\mathrm{ZnCl}_{2}\right)$ are not thermodynamically stable (see Fig. 16b).

Based on the C 1s high-resolution spectra (not shown here), an additional inner peak at $290.97 \mathrm{eV}$ was assigned to the presence of hydrozincite $\left(\mathrm{Zn}_{5}\left(\mathrm{CO}_{3}\right)_{2}(\mathrm{OH})_{6}\right)[60,61]$. The $\mathrm{O} 1 \mathrm{~s}$ core level (not shown here) was deconvoluted with three additional contributions compared to the $\mathrm{O} 1 \mathrm{~s}$ core level for CNT-60ZRP. A peak at $530 \mathrm{eV}$ was attributed to zinc oxide ( $\mathrm{ZnO})$, one at $532 \mathrm{eV}$ was assigned to the presence of zinc hydroxide, and one at $531.4 \mathrm{eV}$ was related to

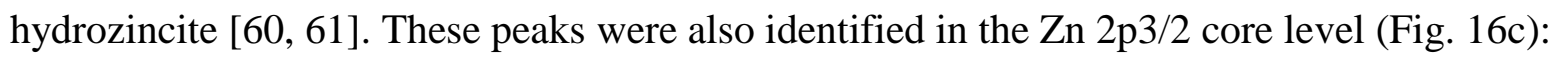
zinc oxide $(\mathrm{ZnO})$ at $1020.65 \mathrm{eV}$, zinc hydroxide $\left(\mathrm{Zn}(\mathrm{OH})_{2}\right)$ at $1023.97 \mathrm{eV}$, hydrozincite $\left(\mathrm{Zn}_{5}\left(\mathrm{CO}_{3}\right)_{2}(\mathrm{OH})_{6}\right)$ at $1022.46 \mathrm{eV}$, and an additional peak at $1019.29 \mathrm{eV}$ assigned to metallic zinc $[60,61]$. Based on these identified chemical species, the mechanism of zinc dissolution in alkaline medium can be described as follows [62]: 
$\mathrm{Zn}+2 \mathrm{OH}^{-} \rightarrow \mathrm{Zn}(\mathrm{OH})_{2}+2 \mathrm{e}^{-}$

$\mathrm{Zn}(\mathrm{OH})_{2}+2 \mathrm{e}^{-} \rightarrow \mathrm{Zn}(\mathrm{OH})_{4}^{=}$(zincate ions)

$\mathrm{Zn}(\mathrm{OH})_{4}^{\bar{x}} \rightarrow \mathrm{ZnO}+2 \mathrm{OH}^{-}+2 \mathrm{H}_{2} \mathrm{O}$

Initially, zinc hydroxide is formed due to dissolution of the zinc particles. Afterwards, zincate ions can be produced owing to the alkaline $\mathrm{pH}$ of the simulated concrete pore solution. Finally, these zincate ions can undergo an additional conversion to zinc oxide. Further transformation occurs due to the presence of carbon dioxide, which can be absorbed or dissolved from the environment into the electrolyte and lead to the formation of hydrozincite $\left(\mathrm{Zn}_{5}\left(\mathrm{CO}_{3}\right)_{2}(\mathrm{OH})_{6}[62]:\right.$

$5 \mathrm{Zn}(\mathrm{OH})_{4}^{\bar{y}}+2 \mathrm{CO}_{2} \rightarrow\left(\mathrm{Zn}_{5}\left(\mathrm{CO}_{3}\right)_{2}(\mathrm{OH})_{6}+10 \mathrm{OH}^{-}+2 \mathrm{H}_{2} \mathrm{O}\right.$

Hydrozincite could also be formed during the storage time of the sample before performing XPS analysis. This results from direct interaction of the zinc corrosion products with the $\mathrm{CO}_{2}$ in air [63]:

$5 \mathrm{Zn}(\mathrm{OH})_{2}(\mathrm{~s})+2 \mathrm{CO}_{2}(\mathrm{~g}) \rightarrow\left(\mathrm{Zn}_{5}\left(\mathrm{CO}_{3}\right)_{2}(\mathrm{OH})_{6}+2 \mathrm{H}_{2} \mathrm{O}\right.$

Fig. 17 shows the XPS spectra for CNT-80ZRP. The same species were found as in CNT-70ZRP. However, the distribution of the chemical composition in the $\mathrm{O} 1 \mathrm{~s}$ core level shows that the amount of zinc corrosion products increased with respect to the magnitudes for CNT-70ZRP. This behaviour is expected based on the SEM images, in which a well-defined layer of zinc corrosion products was formed on the surface of CNT-80ZRP. In contrast, no layer was observed for CNT-70ZRP, and there were only a few agglomerates of zinc corrosion products. The higher amount of zinc corrosion products on the surface of the coating demonstrates the high galvanic process provided by the zinc particles. In the same way, the concentration of zinc corrosion products for CNT-90ZRP was higher than for CNT-80ZRP due to the extended cathodic protection. This allows for higher accumulation of zinc corrosion 
products on the surface of the epoxy coating. This is clearly shown in Fig. 18a, where the percentage of zinc corrosion products on the $\mathrm{O} 1 \mathrm{~s}$ core level increases with the amount of zinc particles introduced to the epoxy binder. A higher amount of zinc corrosion products was formed with increased zinc particle concentration. However, Fig. 18b shows that as the amount of zinc particles increased in the epoxy binder, a higher content of metallic zinc was found at the coating surface. This means that some zinc particles did not contribute to the cathodic protection process.

\section{Conclusions}

- The corrosion protection mechanisms were examined for carbon nanotubes and zinc-rich epoxy primers with different zinc content in a simulated concrete pore solution in the presence of chloride ions. Three different mechanisms were identified based on electrochemical techniques. Predominantly barrier-type corrosion protection was provided by CNT-60ZRP due to low porosity of the epoxy binder and the positive effect of CNTs as pore fillers. A mixed corrosion protection mechanism was identified for CNT-70ZRP, where barrier protection, cathodic protection, and faradaic processes on the zinc particles were observed. Finally, a predominant cathodic protection mechanism was observed for CNT80ZRP and CNT-90ZRP due to higher amount of zinc particles and presence of CNTs that enhances the electron transfer between zinc particles and the carbon steel surface.

- The anticorrosive performance of a zinc-rich epoxy primer with $70 \mathrm{wt} \% \mathrm{Zn}$ and without the presence of CNTs was also investigated by electrochemical and morphology techniques. This formulation did not provide cathodic protection, but there were charge transfer processes involving the carbon steel surface. Therefore, it was concluded that CNTs have a positive effect on the protection mechanism of zinc-rich epoxy primers. The CNTs might help in the electronic connection between the zinc particles among themselves and with the carbon steel surface.

- For CNT-ZRPs with $80 \mathrm{wt} \% \mathrm{Zn}$ and $90 \mathrm{wt} \% \mathrm{Zn}$, effective cathodic protection was predominant producing the formation of a barrier layer of zinc corrosion products that increased the total resistance of the system. EDS and XPS analysis showed that the protective 
layer formed at the coating surface was mainly composed of zinc oxide, zinc hydroxide, and hydrozincite.

\section{Acknowledgments}

The authors would like to thank TESLA Nano coatings Co. for the samples provided and Dr. Jorma Virtanen for his technical discussion and contribution to this work.

\section{References}

[1] W. Morris, M. Vázquez, S.R. De Sánchez, Efficiency of coatings applied on rebars in concrete, Journal of Materials Science, 35 (2000) 1885-1890.

[2] J. Wei, X.X. Fu, J.H. Dong, W. Ke, Corrosion Evolution of Reinforcing Steel in Concrete under Dry/Wet Cyclic Conditions Contaminated with Chloride, Journal of Materials Science \& Technology, 28 (2012) 905-912.

[3] C.-Q. Ye, R.-G. Hu, S.-G. Dong, X.-J. Zhang, R.-Q. Hou, R.-G. Du, C.-J. Lin, J.-S. Pan, EIS analysis on chloride-induced corrosion behavior of reinforcement steel in simulated carbonated concrete pore solutions, Journal of Electroanalytical Chemistry, 688 (2013) 275-281.

[4] S.M. Abd El Haleem, E.E. Abd El Aal, S. Abd El Wanees, A. Diab, Environmental factors affecting the corrosion behaviour of reinforcing steel: I. The early stage of passive film formation in $\mathrm{Ca}(\mathrm{OH}) 2$ solutions, Corrosion Science, 52 (2010) 3875-3882.

[5] F. Belaid, G. Arliguie, R. Francois, Corrosion products of galvanized rebars embedded in chloride-contaminated concrete, Corrosion, 56 (2000) 960-965.

[6] S.A. El Haleem, S.A. El Wanees, E.A. El Aal, A. Diab, Environmental factors affecting the corrosion behavior of reinforcing steel II. Role of some anions in the initiation and inhibition of pitting corrosion of steel in $\mathrm{Ca}(\mathrm{OH}) 2$ solutions, corrosion Science, 52 (2010) 292-302.

[7] X. Feng, Y. Tang, Y. Zuo, Influence of stress on passive behaviour of steel bars in concrete pore solution, Corrosion Science, 53 (2011) 1304-1311.

[8] M. Moreno, W. Morris, M. Alvarez, G. Duffó, Corrosion of reinforcing steel in simulated concrete pore solutions: effect of carbonation and chloride content, Corrosion Science, 46 (2004) 2681-2699.

[9] X. Shi, N. Xie, K. Fortune, J. Gong, Durability of steel reinforced concrete in chloride environments: An overview, Construction and Building Materials, 30 (2012) 125-138.

[10] S. Ahmad, Reinforcement corrosion in concrete structures, its monitoring and service life prediction - a review, Cement and Concrete Composites, 25 (2003) 459-471.

[11] F. Tang, G. Chen, R.K. Brow, J.S. Volz, M.L. Koenigstein, Corrosion resistance and mechanism of steel rebar coated with three types of enamel, Corrosion Science, 59 (2012) 157168.

[12] S. Pour-Ali, C. Dehghanian, A. Kosari, Corrosion protection of the reinforcing steels in chloride-laden concrete environment through epoxy/polyaniline-camphorsulfonate nanocomposite coating, Corrosion Science, 90 (2015) 239-247. 
[13] R. Selvaraj, M. Selvaraj, S. Iyer, Studies on the evaluation of the performance of organic coatings used for the prevention of corrosion of steel rebars in concrete structures, Progress in organic coatings, 64 (2009) 454-459.

[14] K. Saravanan, S. Sathiyanarayanan, S. Muralidharan, S.S. Azim, G. Venkatachari, Performance evaluation of polyaniline pigmented epoxy coating for corrosion protection of steel in concrete environment, Progress in organic coatings, 59 (2007) 160-167.

[15] G. Batis, P. Pantazopoulou, A. Routoulas, Corrosion protection investigation of reinforcement by inorganic coating in the presence of alkanolamine-based inhibitor, Cement and Concrete Composites, 25 (2003) 371-377.

[16] H. Marchebois, M. Keddam, C. Savall, J. Bernard, S. Touzain, Zinc-rich powder coatings characterisation in artificial sea water: EIS analysis of the galvanic action, Electrochimica Acta, 49 (2004) 1719-1729.

[17] H.Y. Li, J.Y. Duan, D.D. Wei, Comparison on corrosion behaviour of arc sprayed and zincrich coatings, Surface and Coatings Technology, 235 (2013) 259-266.

[18] B. Ramezanzadeh, S.Y. Arman, M. Mehdipour, Anticorrosion properties of an epoxy zincrich composite coating reinforced with zinc, aluminum, and iron oxide pigments, J Coat Technol Res, 11 (2014) 727-737.

[19] K. Schaefer, A. Miszczyk, Improvement of electrochemical action of zinc-rich paints by addition of nanoparticulate zinc, Corrosion Science, 66 (2013) 380-391.

[20] S. Park, M. Shon, Effects of multi-walled carbon nano tubes on corrosion protection of zinc rich epoxy resin coating, Journal of Industrial and Engineering Chemistry, 21 (2015) 1258-1264. [21] A. Gergely, É. Pfeifer, I. Bertóti, T. Török, E. Kálmán, Corrosion protection of cold-rolled steel by zinc-rich epoxy paint coatings loaded with nano-size alumina supported polypyrrole, Corrosion Science, 53 (2011) 3486-3499.

[22] A. Gergely, I. Bertóti, T. Török, É. Pfeifer, E. Kálmán, Corrosion protection with zinc-rich epoxy paint coatings embedded with various amounts of highly dispersed polypyrrole-deposited alumina monohydrate particles, Progress in Organic Coatings, 76 (2013) 17-32.

[23] A. Gergely, Z. Pászti, J. Mihály, E. Drotár, T. Török, Galvanic function of zinc-rich coatings facilitated by percolating structure of the carbon nanotubes. Part II: Protection properties and mechanism of the hybrid coatings, Progress in Organic Coatings, 77 (2014) 412424.

[24] P. Hammer, F. dos Santos, B. Cerrutti, S. Pulcinelli, C. Santilli, Carbon nanotube-reinforced siloxane-PMMA hybrid coatings with high corrosion resistance, Progress in Organic Coatings, 76 (2013) 601-608.

[25] P.P. Deshpande, S.S. Vathare, S.T. Vagge, E. Tomšík, J. Stejskal, Conducting polyaniline/multi-wall carbon nanotubes composite paints on low carbon steel for corrosion protection: electrochemical investigations, Chemical Papers, 67 (2013) 1072-1078.

[26] M.C. Turhan, Q. Li, H. Jha, R.F. Singer, S. Virtanen, Corrosion behaviour of multiwall carbon nanotube/magnesium composites in 3.5\% NaCl, Electrochimica Acta, 56 (2011) 71417148 .

[27] H. Jeon, J. Park, M. Shon, Corrosion protection by epoxy coating containing multi-walled carbon nanotubes, Journal of Industrial and Engineering Chemistry, 19 (2013) 849-853. [28] X. Chen, C. Chen, H. Xiao, F. Cheng, G. Zhang, G. Yi, Corrosion behavior of carbon nanotubes-Ni composite coating, Surface and Coatings Technology, 191 (2005) 351-356. [29] L. Yang, F. Liu, E. Han, Effects of P/B on the properties of anticorrosive coatings with different particle size, Progress in Organic Coatings, 53 (2005) 91-98. 
[30] D. Hausmann, Steel corrosion in concrete--How does it occur?, Materials protection, (1967).

[31] C. Andrade, C. Page, Pore solution chemistry and corrosion in hydrated cement systems containing chloride salts: a study of cation specific effects, British Corrosion Journal, 21 (1986) 49-54.

[32] M. Hurley, J. Scully, Threshold chloride concentrations of selected corrosion-resistant rebar materials compared to carbon steel, Corrosion, 62 (2006) 892-904.

[33] F. Zhang, J. Pan, C. Lin, Localized corrosion behaviour of reinforcement steel in simulated concrete pore solution, Corrosion Science, 51 (2009) 2130-2138.

[34] J. Singh, D. Singh, The nature of rusts and corrosion characteristics of low alloy and plain carbon steels in three kinds of concrete pore solution with salinity and different $\mathrm{pH}$, Corrosion Science, 56 (2012) 129-142.

[35] K. Andersson, B. Allard, M. Bengtsson, B. Magnusson, Chemical composition of cement pore solutions, Cement and Concrete Research, 19 (1989) 327-332.

[36] P. Ghods, O.B. Isgor, F. Bensebaa, D. Kingston, Angle-resolved XPS study of carbon steel passivity and chloride-induced depassivation in simulated concrete pore solution, Corrosion Science, 58 (2012) 159-167.

[37] A. Moragues, A. Macias, C. Andrade, Equilibria of the chemical composition of the concrete pore solution. Part I: Comparative study of synthetic and extracted solutions, Cement and Concrete Research, 17 (1987) 173-182.

[38] J. Williamson, O.B. Isgor, The effect of simulated concrete pore solution composition and chlorides on the electronic properties of passive films on carbon steel rebar, Corrosion Science, (2016).

[39] M. Mouanga, M. Puiggali, B. Tribollet, V. Vivier, N. Pébère, O. Devos, Galvanic corrosion between zinc and carbon steel investigated by local electrochemical impedance spectroscopy, Electrochimica Acta, 88 (2013) 6-14.

[40] J.-B. Jorcin, H. Krawiec, N. Pébère, V. Vignal, Comparison of local electrochemical impedance measurements derived from bi-electrode and microcapillary techniques, Electrochimica Acta, 54 (2009) 5775-5781.

[41] K. Davies, J. Broomfield, Cathodic protection mechanism and a review of criteria, Cathodic Protection of Steel in Concrete and Masonry, 41 (2013).

[42] G.K. Glass, A.M. Hassanein, N.R. Buenfeld, CP criteria for reinforced concrete in marine exposure zones, Journal of materials in civil engineering, 12 (2000) 164-171.

[43] C.M. Abreu, M. Izquierdo, M. Keddam, X.R. Nóvoa, H. Takenouti, Electrochemical behaviour of zinc-rich epoxy paints in 3\% $\mathrm{NaCl}$ solution, Electrochimica Acta, 41 (1996) 24052415.

[44] F. Mansfeld, Use of electrochemical impedance spectroscopy for the study of corrosion protection by polymer coatings, Journal of Applied Electrochemistry, 25 (1995) 187-202.

[45] H. Marchebois, S. Joiret, C. Savall, J. Bernard, S. Touzain, Characterization of zinc-rich powder coatings by EIS and Raman spectroscopy, Surface and Coatings Technology, 157 (2002) 151-161.

[46] C. Abreu, M. Izquierdo, P. Merino, X. Novoa, C. Perez, A new approach to the determination of the cathodic protection period in zinc-rich paints, Corrosion, 55 (1999) 11731181.

[47] R. Armas, C. Gervasi, A. Di Sarli, S. Real, J. Vilche, Zinc-rich paints on steels in artificial seawater by electrochemical impedance spectroscopy, Corrosion, 48 (1992) 379-383. 
[48] S. Feliú, R. Barajas, J.M. Bastidas, M. Morcillo, Study of protection mechanisms of zincrich paints by electrochemical impedance spectroscopy, ASTM SPECIAL TECHNICAL PUBLICATION, 1188 (1993) 438-438.

[49] F.J. Recio, M.C. Alonso, L. Gaillet, M. Sánchez, Hydrogen embrittlement risk of high strength galvanized steel in contact with alkaline media, Corrosion Science, 53 (2011) 28532860.

[50] S. Shen, Y. Zuo, The improved performance of Mg-rich epoxy primer on AZ91D magnesium alloy by addition of $\mathrm{ZnO}$, Corrosion Science, 87 (2014) 167-178.

[51] S. Shreepathi, P. Bajaj, B. Mallik, Electrochemical impedance spectroscopy investigations of epoxy zinc rich coatings: Role of $\mathrm{Zn}$ content on corrosion protection mechanism, Electrochimica Acta, 55 (2010) 5129-5134.

[52] H.A. Al-Turaif, Surface morphology and chemistry of epoxy-based coatings after exposure to ultraviolet radiation, Progress in Organic Coatings, 76 (2013) 677-681.

[53] G. Xiao, M. Delamar, M. Shanahan, Irreversible interactions between water and

DGEBA/DDA epoxy resin during hygrothermal aging, Journal of Applied Polymer Science, 65 (1997) 449-458.

[54] H.J. Shin, K.K. Kim, A. Benayad, S.M. Yoon, H.K. Park, I.S. Jung, M.H. Jin, H.K. Jeong, J.M. Kim, J.Y. Choi, Efficient reduction of graphite oxide by sodium borohydride and its effect on electrical conductance, Advanced Functional Materials, 19 (2009) 1987-1992.

[55] K. Li, K. Wang, M.-s. Zhan, W. Xu, The change of thermal-mechanical properties and chemical structure of ambient cured DGEBA/TEPA under accelerated thermo-oxidative aging, Polymer Degradation and Stability, 98 (2013) 2340-2346.

[56] J.-H. Zhou, Z.-J. Sui, J. Zhu, P. Li, D. Chen, Y.-C. Dai, W.-K. Yuan, Characterization of surface oxygen complexes on carbon nanofibers by TPD, XPS and FT-IR, Carbon, 45 (2007) 785-796.

[57] R. Rajagopalan, J.O. Iroh, Characterization of polyaniline-polypyrrole composite coatings on low carbon steel: a XPS and infrared spectroscopy study, Applied Surface Science, 218 (2003) 58-69.

[58] M. Liu, P. Wu, Y. Ding, G. Chen, S. Li, Two-dimensional (2D) ATR-FTIR spectroscopic study on water diffusion in cured epoxy resins, Macromolecules, 35 (2002) 5500-5507.

[59] J. Mijovic, H. Zhang, Local dynamics and molecular origin of polymer network-water interactions as studied by broadband dielectric relaxation spectroscopy, FTIR, and molecular simulations, Macromolecules, 36 (2003) 1279-1288.

[60] E. Diler, S. Rioual, B. Lescop, D. Thierry, B. Rouvellou, Chemistry of corrosion products of $\mathrm{Zn}$ and MgZn pure phases under atmospheric conditions, Corrosion science, 65 (2012) 178-186.

[61] J. Duchoslav, R. Steinberger, M. Arndt, T. Keppert, G. Luckeneder, K. Stellnberger, J. Hagler, G. Angeli, C. Riener, D. Stifter, Evolution of the surface chemistry of hot dip galvanized $\mathrm{Zn}-\mathrm{Mg}-\mathrm{Al}$ and $\mathrm{Zn}$ coatings on steel during short term exposure to sodium chloride containing environments, Corrosion Science, 91 (2015) 311-320.

[62] R. Ghosh, D.D.N. Singh, Kinetics, mechanism and characterisation of passive film formed on hot dip galvanized coating exposed in simulated concrete pore solution, Surface and Coatings Technology, 201 (2007) 7346-7359.

[63] J. Duchoslav, R. Steinberger, M. Arndt, T. Keppert, G. Luckeneder, K.H. Stellnberger, J. Hagler, G. Angeli, C.K. Riener, D. Stifter, Evolution of the surface chemistry of hot dip galvanized $\mathrm{Zn}-\mathrm{Mg}-\mathrm{Al}$ and $\mathrm{Zn}$ coatings on steel during short term exposure to sodium chloride containing environments, Corrosion Science, 91 (2015) 311-320. 


\section{FIGURES}

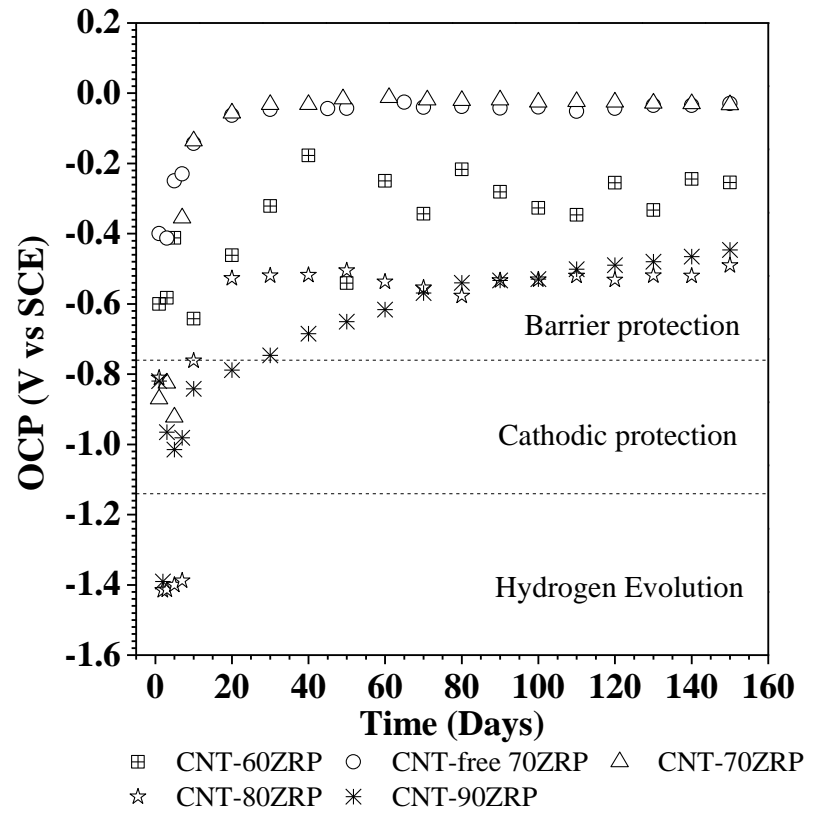

Fig. 1. OCP evolution for CNT-ZRPs with different zinc contents immersed in the SCP solution during 150 days. 

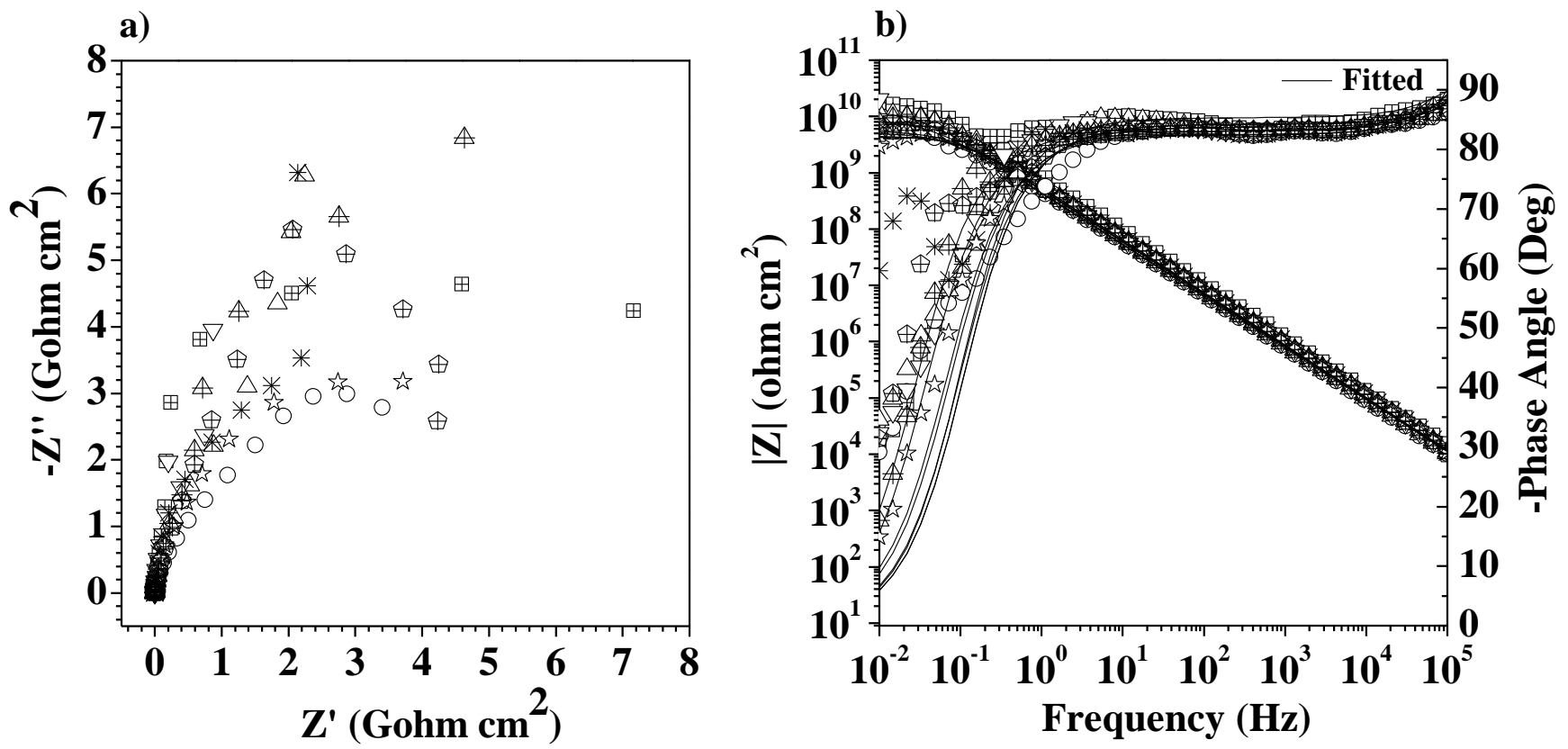

$\boxplus$ Day $1 \bigcirc$ Day $5 \triangle$ Day $10 \nabla$ Day 20

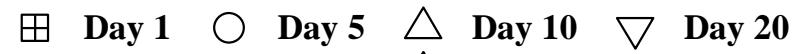
* Day 45 论 Day 65 Day $100 \oplus$ Day 150

Fig. 2. Electrochemical impedance spectra of carbon steel substrate coated with CNT-60ZRP at different immersion times in the SCP solution. a) Nyquist diagram b) Bode diagram. 

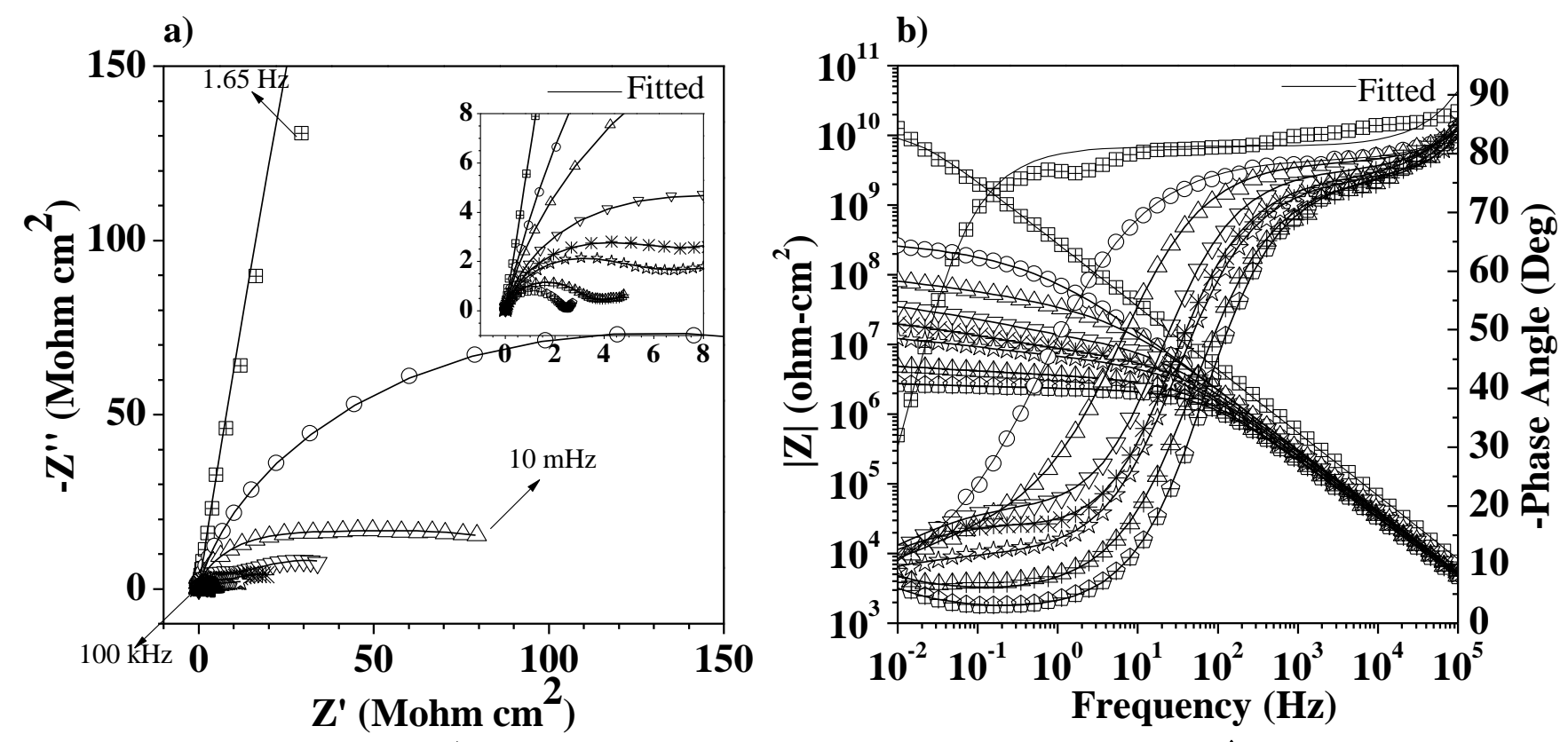

$\boxplus$ Day $1 \bigcirc$ Day $5 \triangle$ Day $10 \nabla$ Day 20

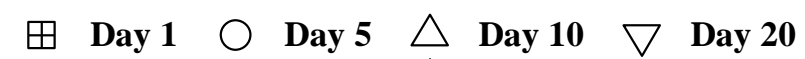
* Day 45 is Day 65 Day $100 \oplus$ Day 150

*

Day 45 is

Day 65

Day $100 \oplus$

Day 150

Fig. 3. Electrochemical impedance spectra of carbon steel substrate coated with CNT-70ZRP at different immersion times in the SCP solution. a) Nyquist diagram b) Bode diagram. 

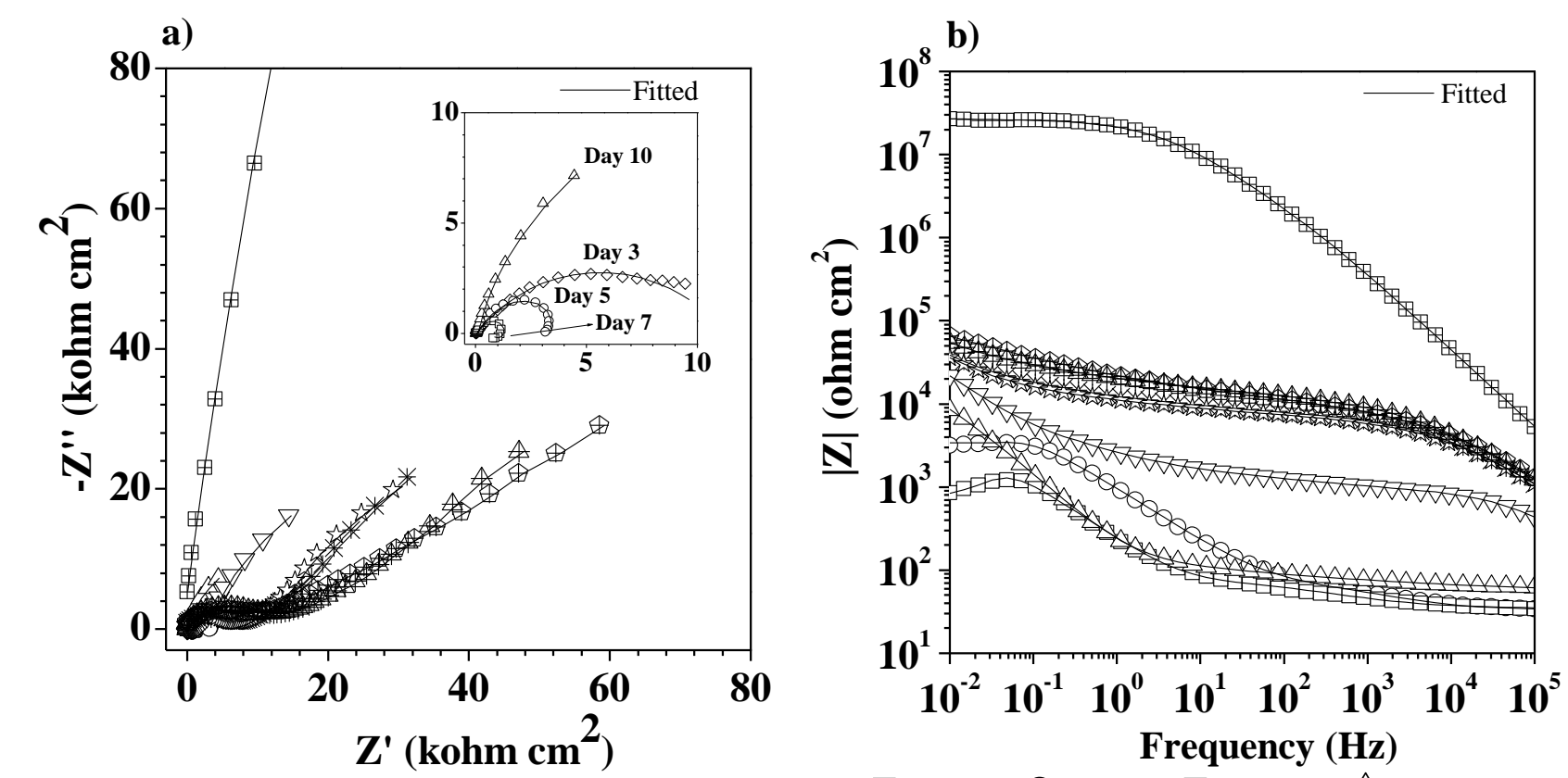

田 Day $1 \oslash$ Day $3 \bigcirc$ Day $5 \square$ Day $7 \triangle$ Day 10 $\nabla$ Day $20 *$ Day 45 放 Day 65 Day $100 \oplus$ Day 150

$\boxplus$ Day $1 \bigcirc \operatorname{Day} 5 \quad \square$ Day $7 \quad \triangle$ Day $10 \nabla$ Day 20 * Day 45 is Day 65 Day $100 \oplus$ Day 150

Fig. 4. Electrochemical impedance spectra of carbon steel substrate coated with CNT-80ZRP at different immersion times in the SCP solution. a) Nyquist diagram b) Bode diagram. 

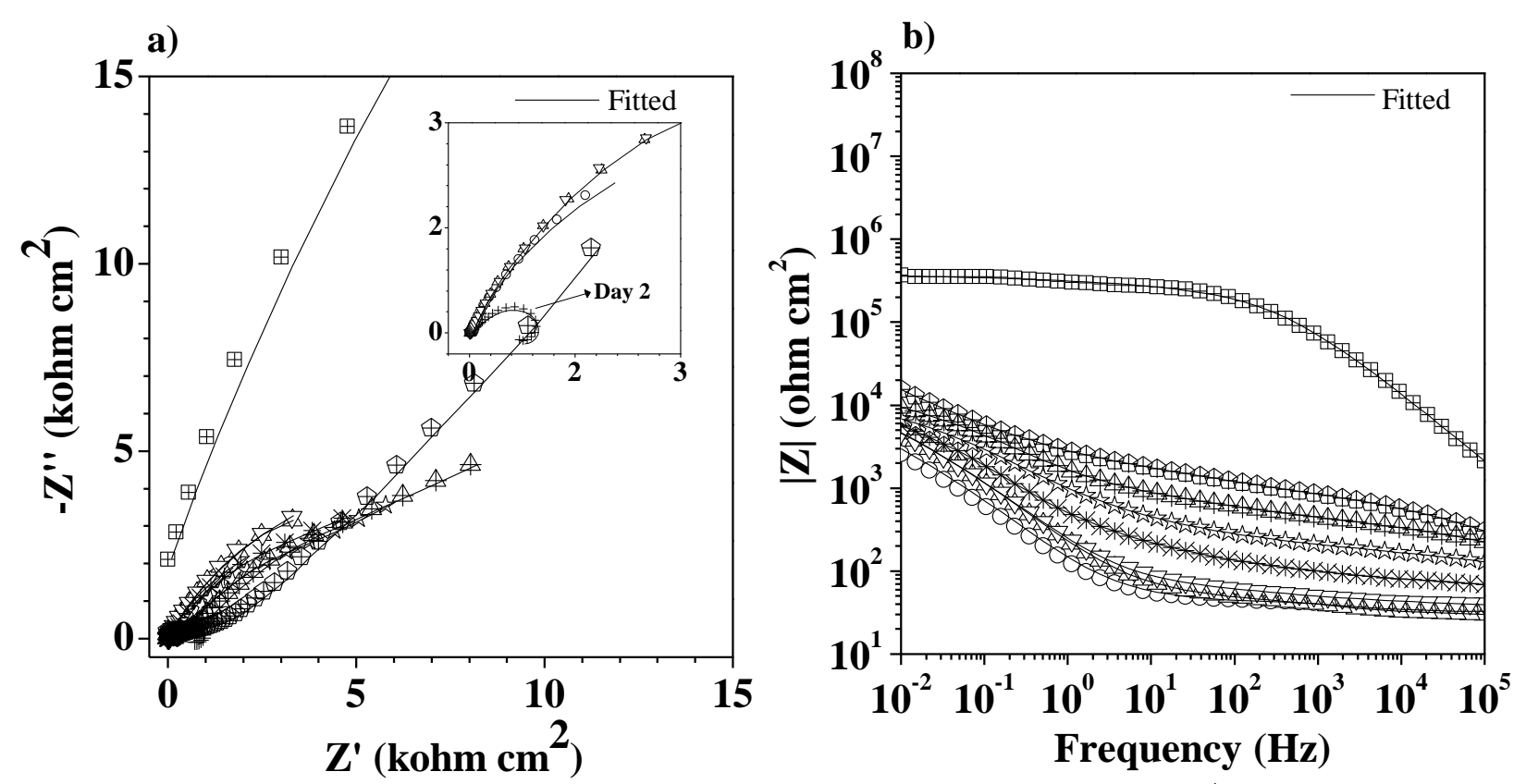

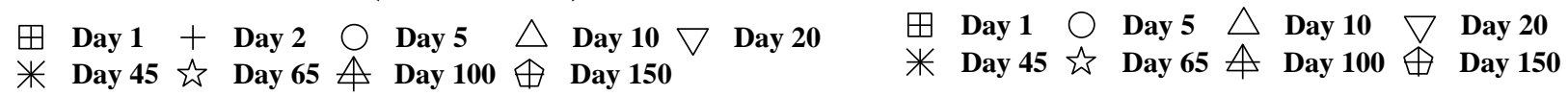

Fig. 5. Electrochemical impedance spectra of carbon steel substrate coated with CNT-90ZRP at different immersion times in the SCP solution. a) Nyquist diagram b) Bode diagram. 

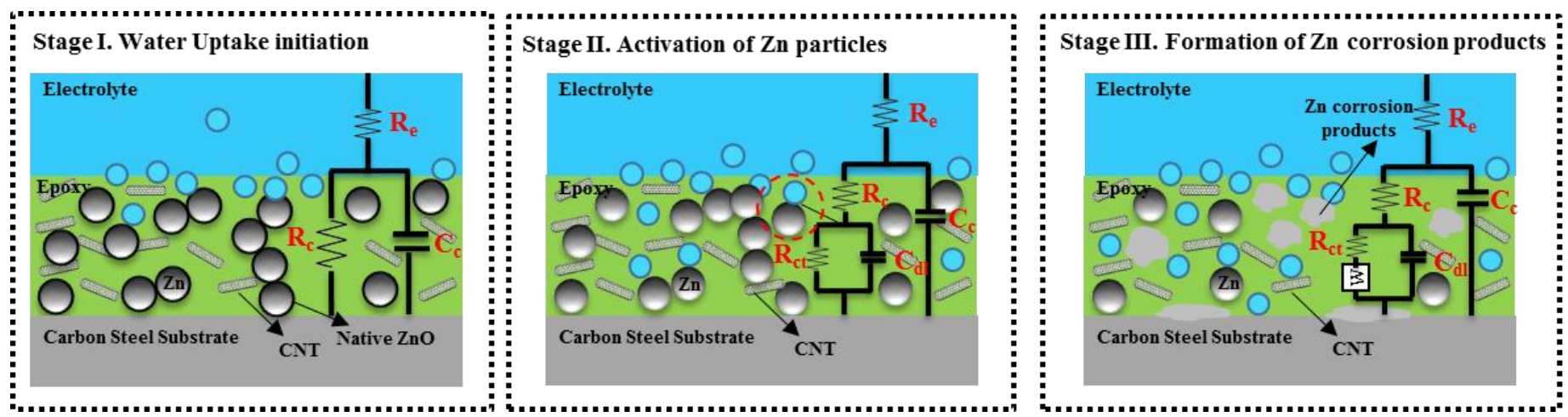

Fig. 6. Electrical equivalent circuits used to fit the impedance spectra of CNT-ZRPs with 60 wt $\%$

$\mathrm{Zn}$ and $70 \mathrm{wt} \% \mathrm{Zn}$. 

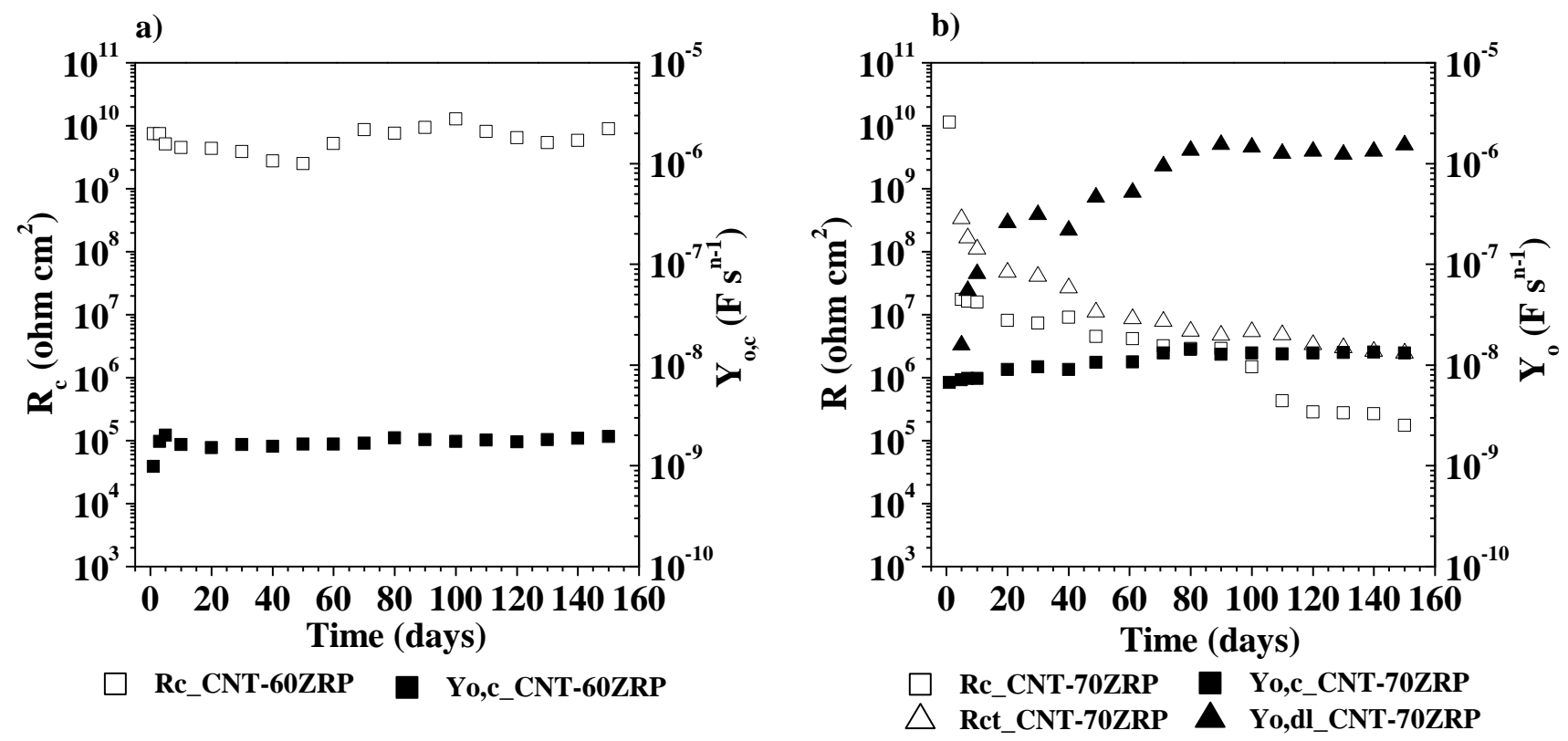

Fig. 7. Evolution of equivalent circuit elements for CNT-60ZRP and CNT-70ZRP exposed to the SCP solution during 150 days. a) CNT-60ZRP b) CNT-70ZRP. 

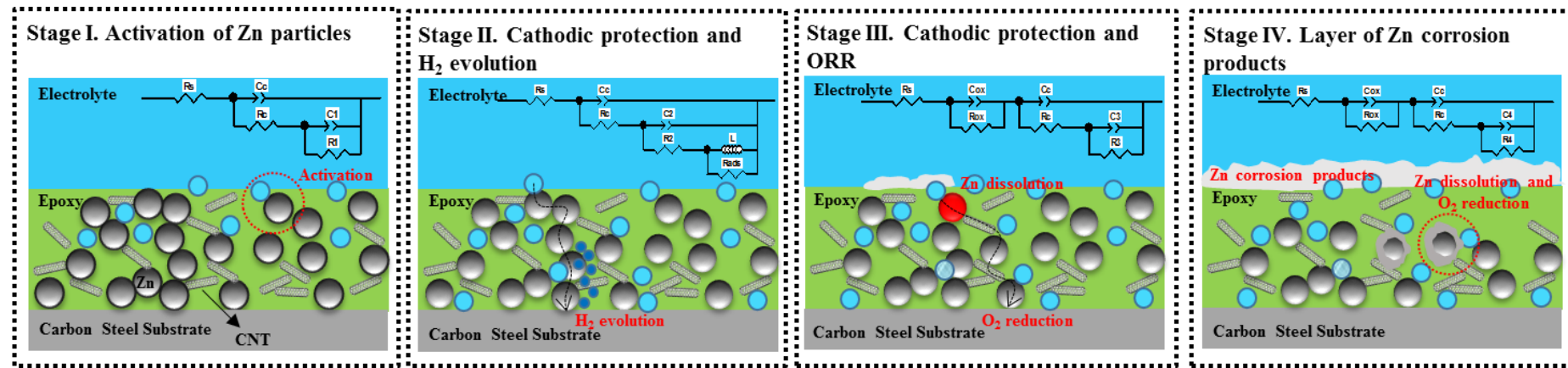

Fig. 8. Electrical equivalent circuits used to fit the impedance spectra of CNT-ZRPs with $80 \mathrm{wt} \%$

$\mathrm{Zn}$ and $90 \mathrm{wt} \% \mathrm{Zn}$. 

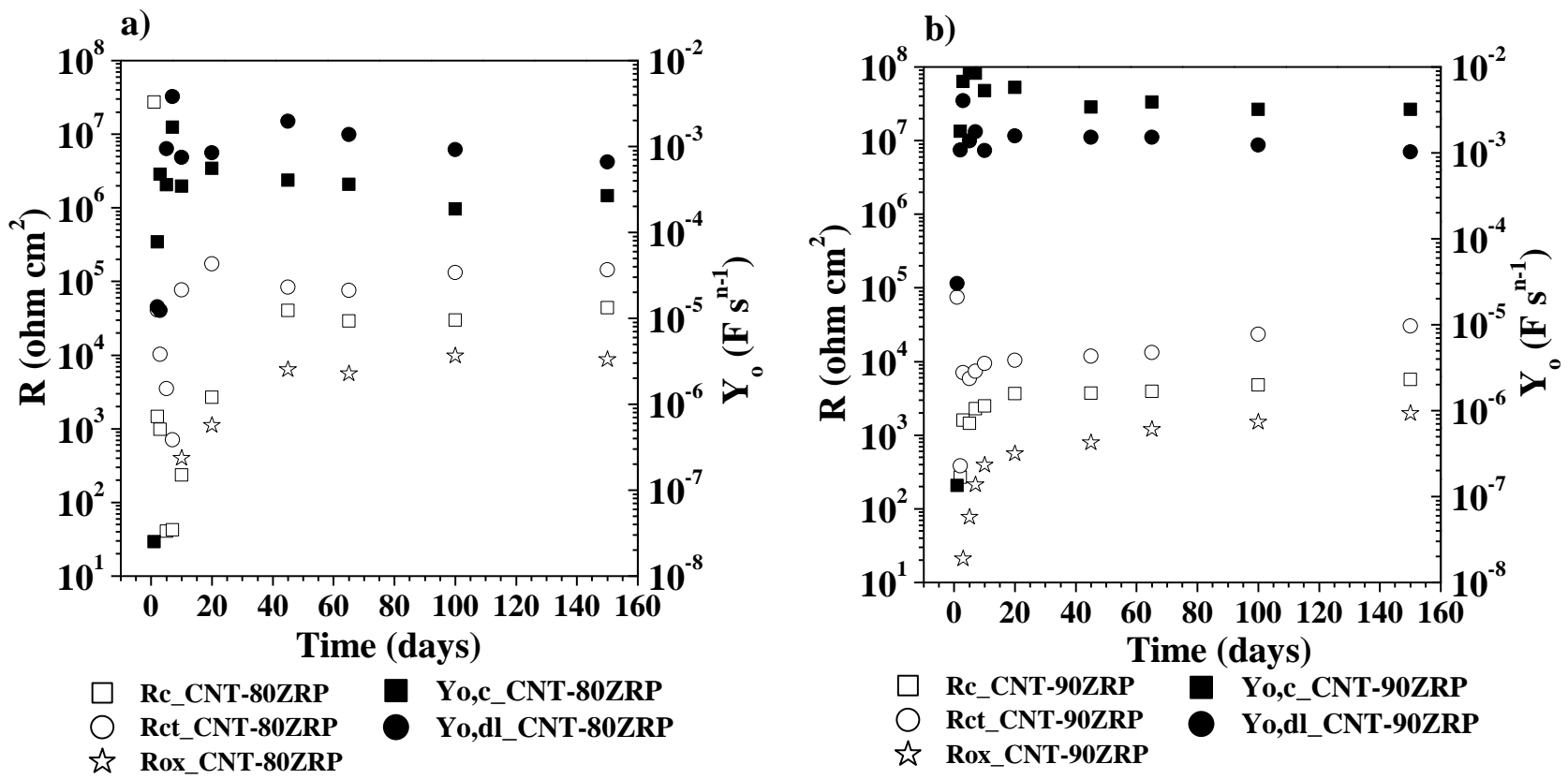

Fig. 9. Evolution of equivalent circuit elements for CNT-80ZRP and CNT-90ZRP exposed to the SCP solution during 150 days. a) CNT-80ZRP. b) CNT-90ZRP 


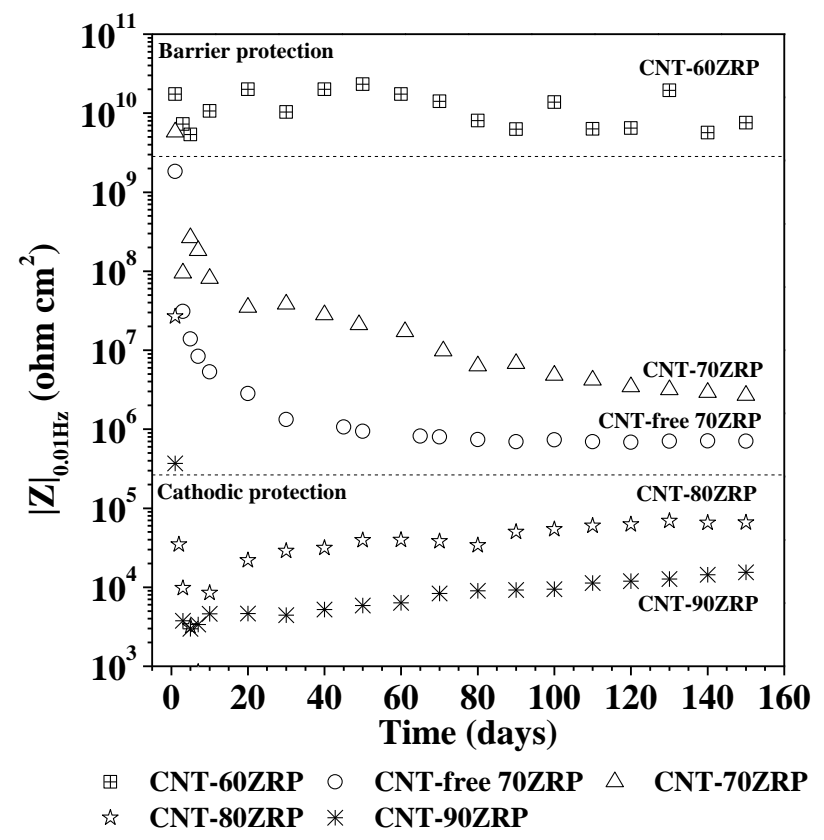

Fig. 10. Evolution of impedance magnitude at $0.01 \mathrm{~Hz}$ for different CNT-ZRP systems immersed in the SCP solution during 150 days. 
a)

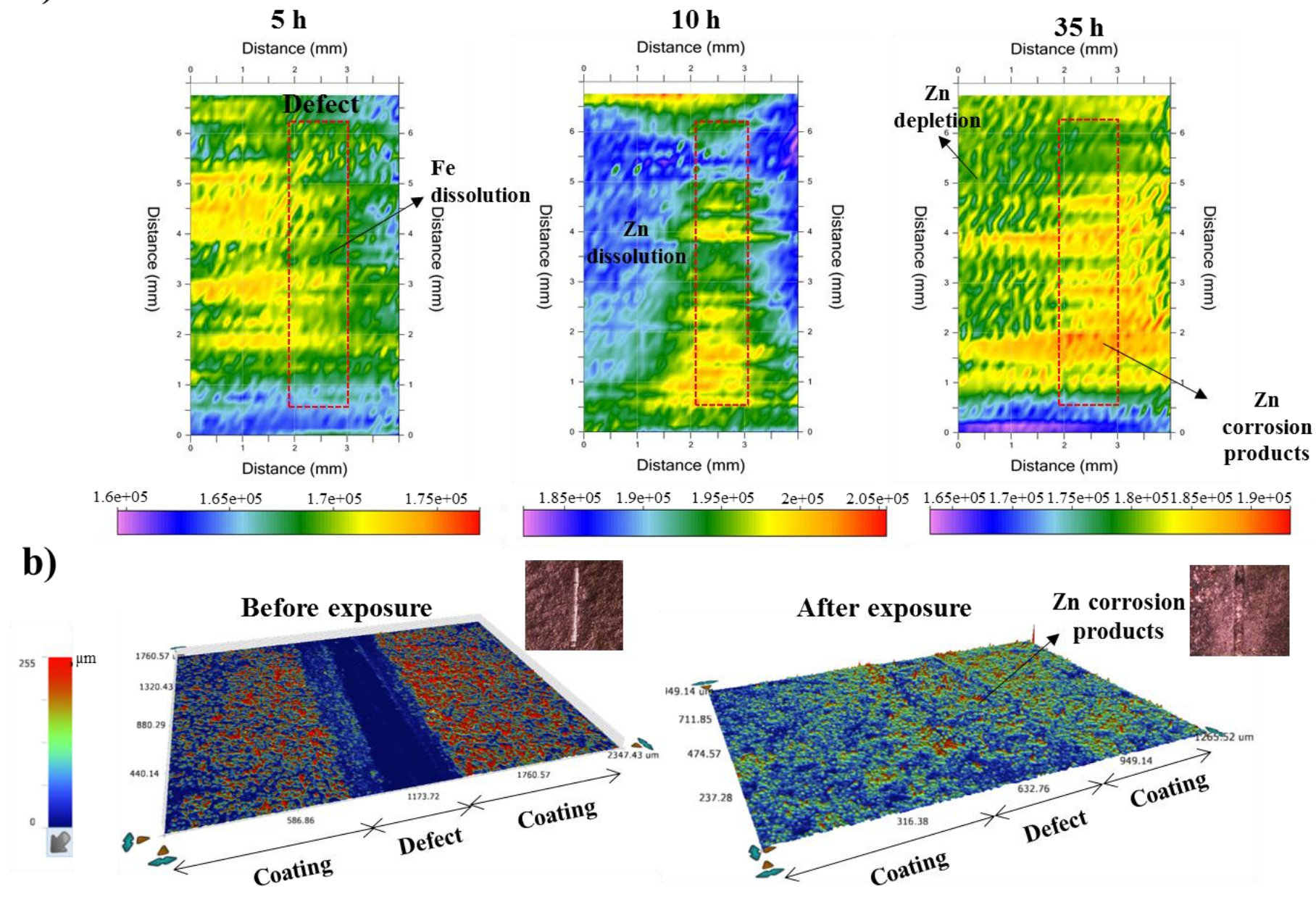

Fig. 11. Local electrochemical impedance spectroscopy (LEIS) results for a scratched CNT90ZRP sample immersed in $0.005 \mathrm{M} \mathrm{NaCl}$ during 48 hours. a) LEIS spectra at $5 \mathrm{~h}, 10 \mathrm{~h}$, and $35 \mathrm{~h}$ after immersion b) 3D microscope images of the sample before and after exposure. 
a)

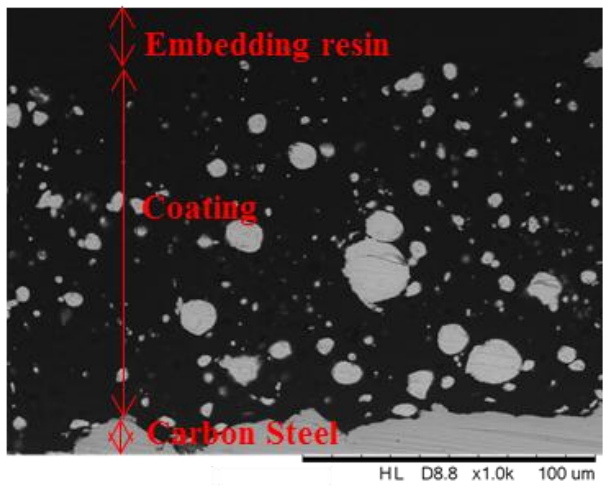

b)

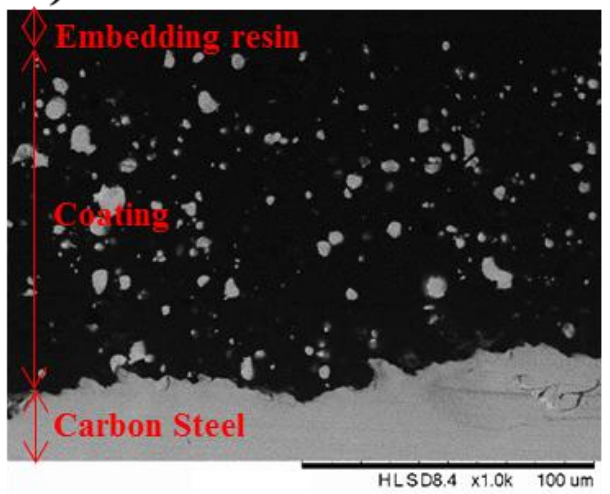

c)

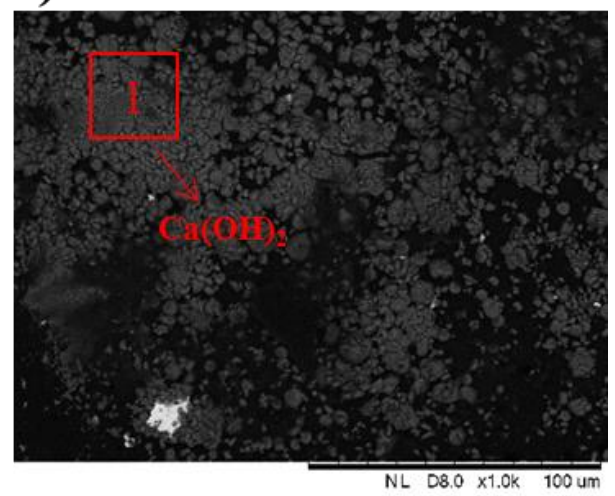

Fig. 12. Cross-section and coating surface images for CNT-60ZRP exposed to the SCP solution.

a) Cross-section of the intact coating. b) Cross-section of the coating exposed for 90 days. c) Surface-view of the coating exposed for 90 days. 
a)

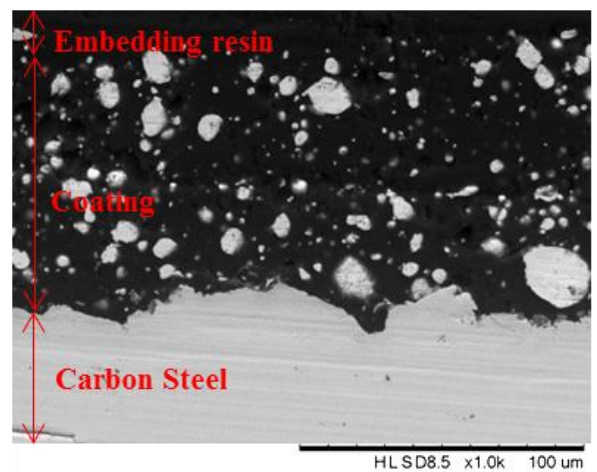

c)

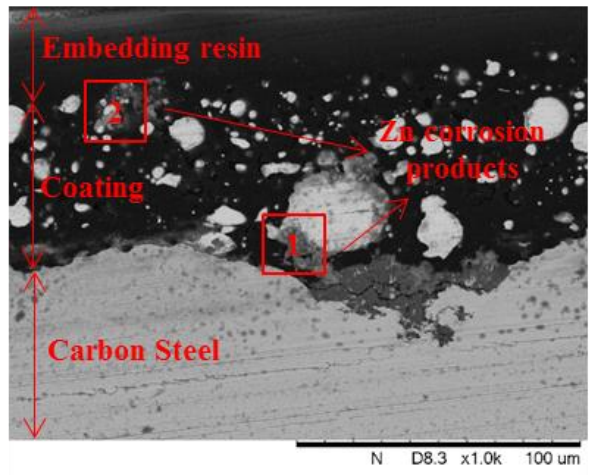

b)

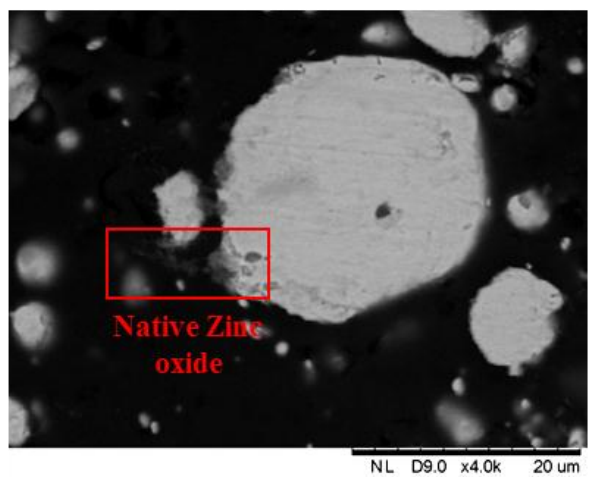

d)

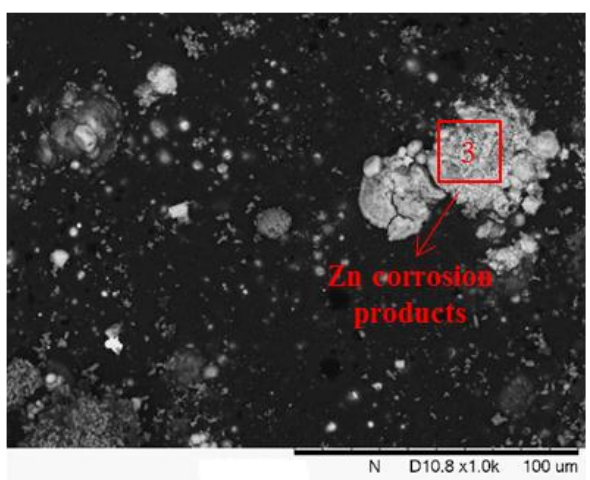

e)

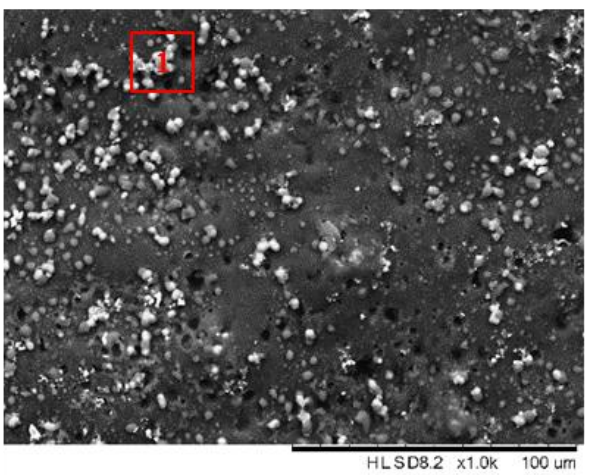

f)

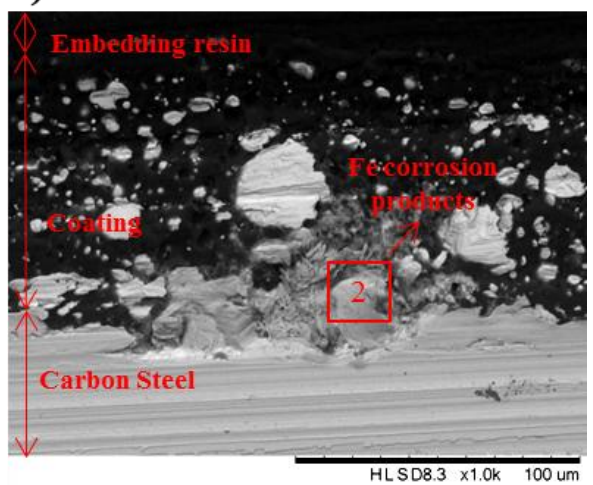

Fig. 13. Cross-section and coating surface images for CNT-70ZRP exposed to the SCP solution at different immersion times. a) Cross-section of intact coating. b) Cross-section after 5 days of immersion. c) Cross-section after 90 days of immersion. d) Surface-view after 90 days of immersion. e) Surface-view of CNT-free 70ZRP after 90 days of immersion. f) Cross-section of CNT-free 70ZRP after 90 days of immersion. 
a)

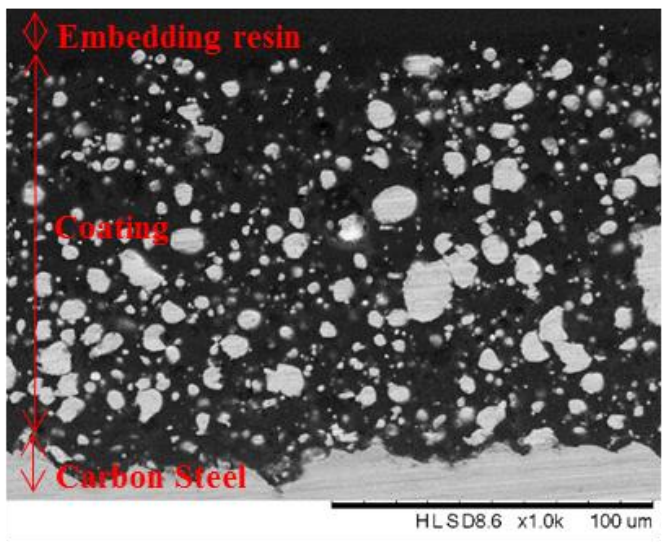

c)

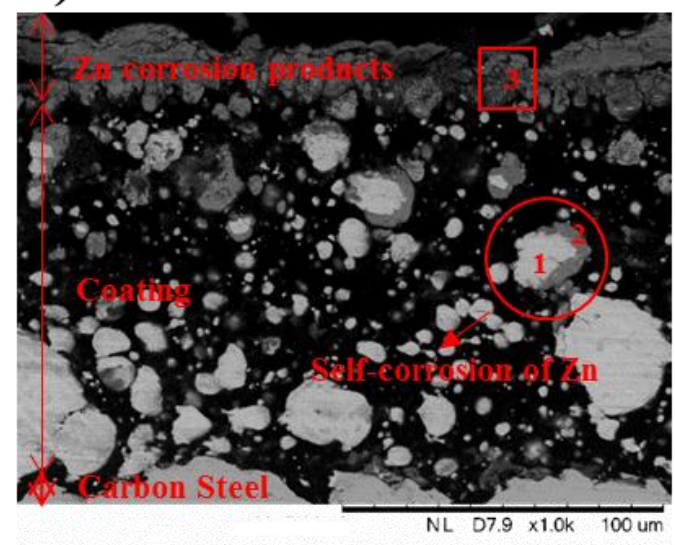

b)

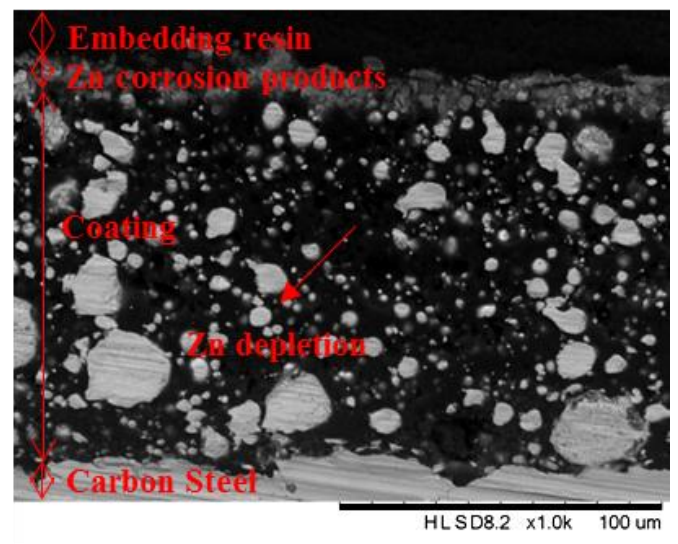

d)

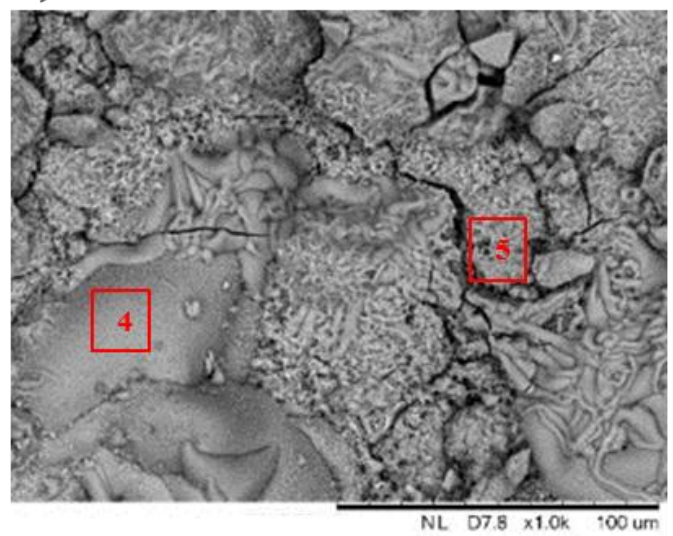

Fig. 14. Cross-section and coating surface images for CNT-80ZRP exposed to the SCP solution at different immersion times. a) Cross-section of intact coating. b) Cross-section after 20 days of immersion. c) Cross-section after 90 days of immersion. d) Surface-view after 90 days of immersion. 

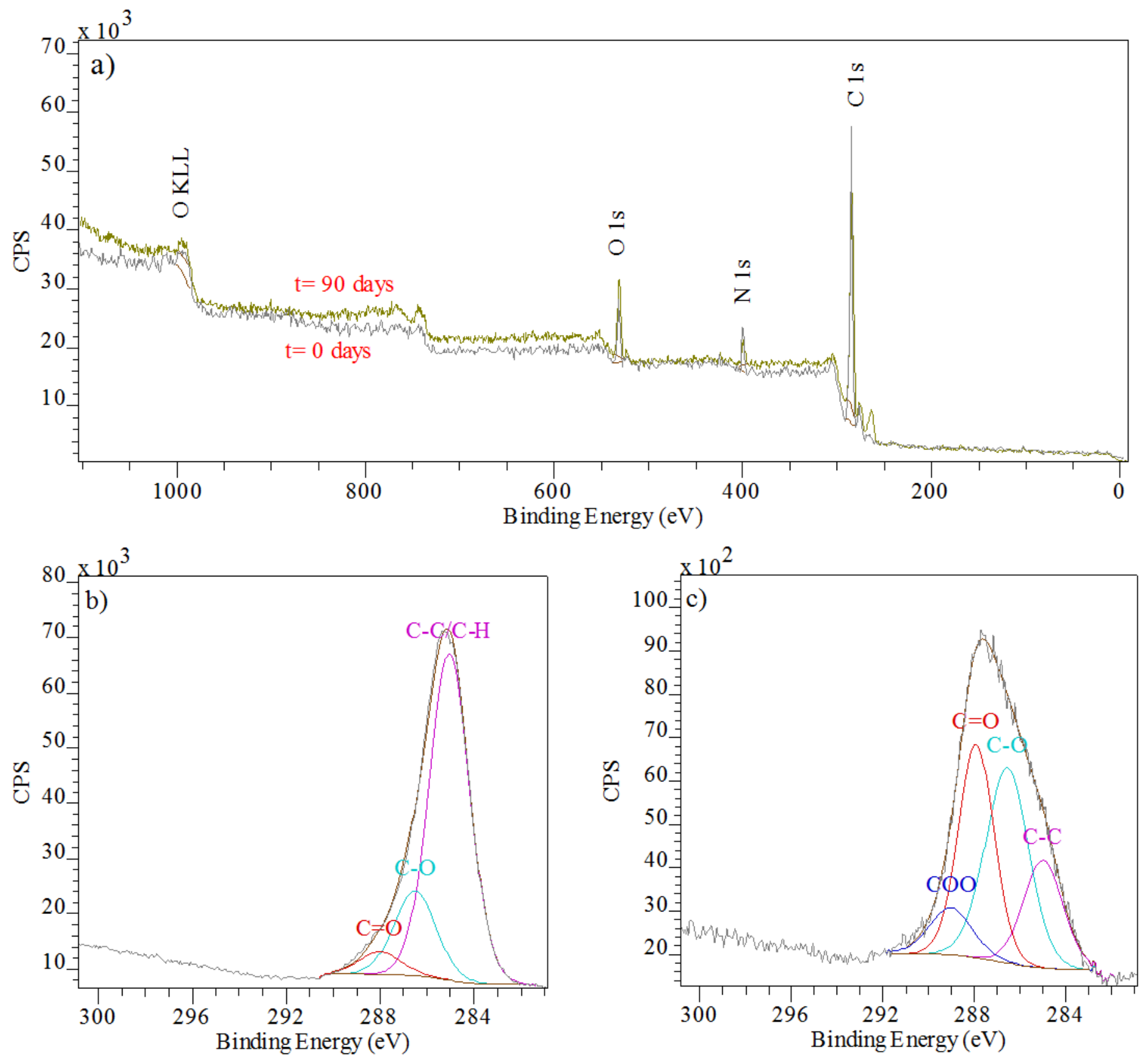

Fig. 15. XPS spectra for CNT-60ZRP before and after exposure to the SCP solution during 90 days. a) Survey spectrum. b) C 1s high-resolution spectrum before immersion. c) C 1s highresolution spectrum after immersion. 

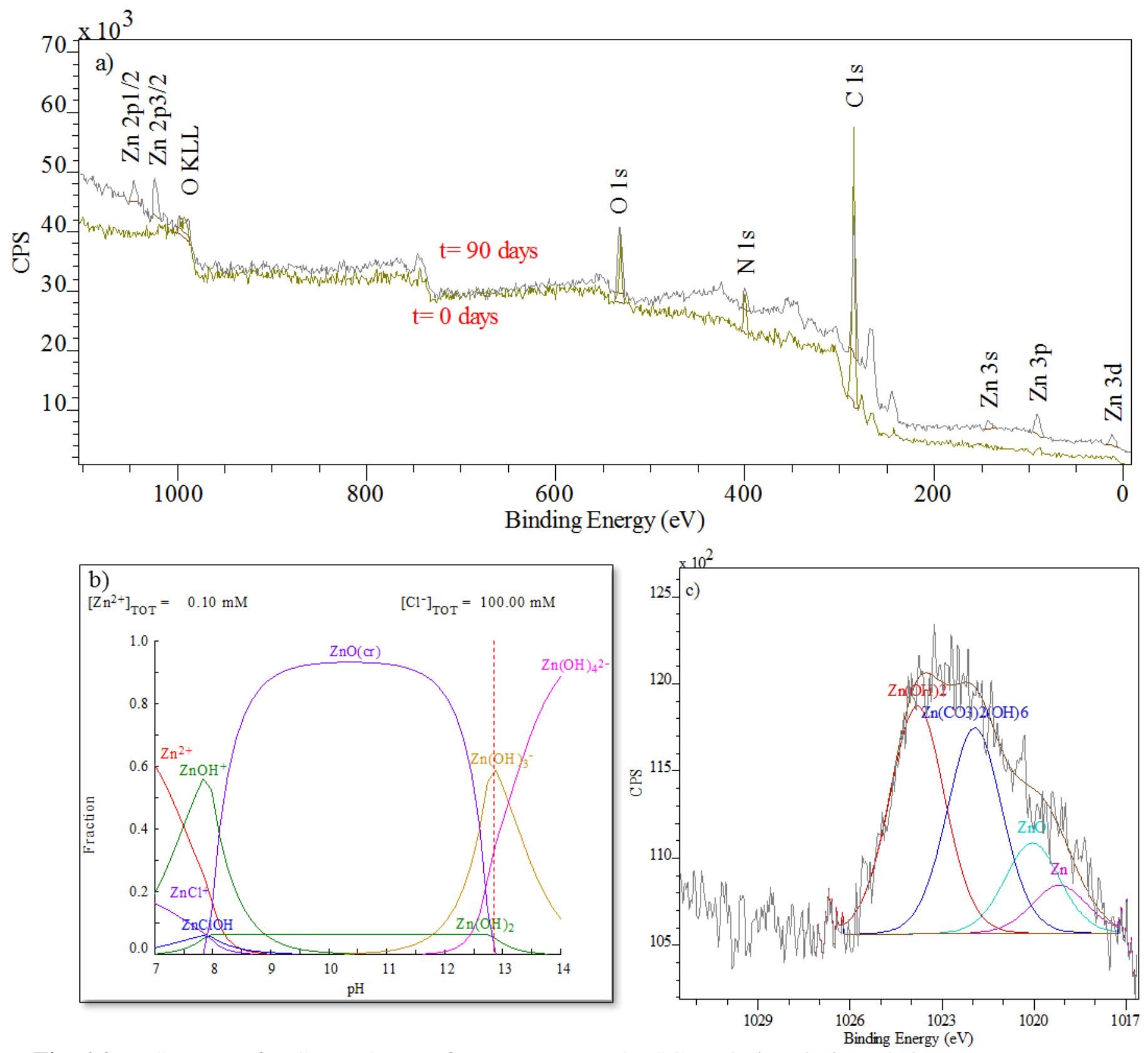

Fig. 16. XPS spectra for CNT-70ZRP after exposure to the SCP solution during 90 days. a)

Survey spectrum. b) Speciation diagram of Zn. c) Zn 2p3/2 high-resolution spectrum. 

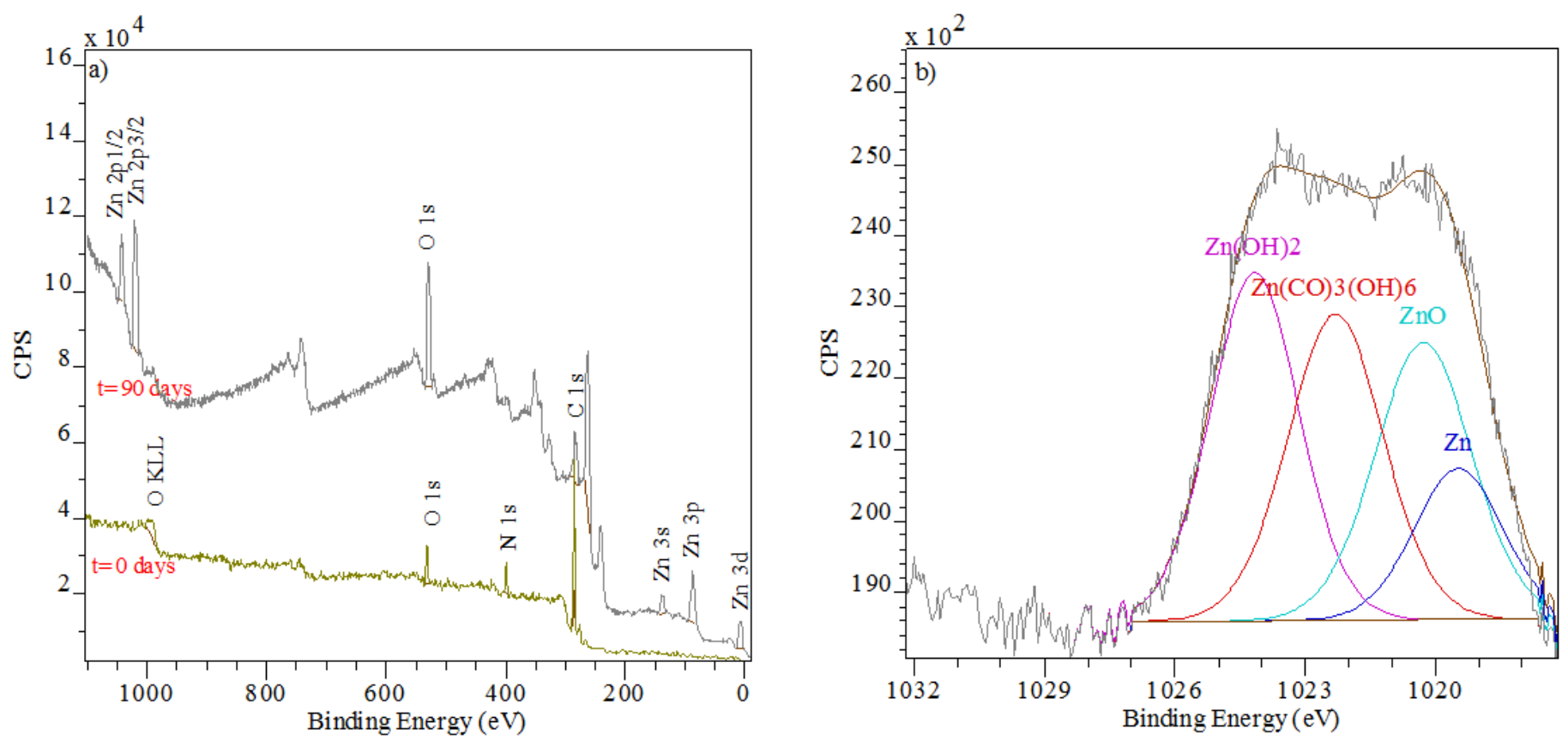

Fig. 17. XPS spectra for CNT-80ZRP after exposure to the SCP solution during 90 days. a)

Survey spectrum. b) Zn 2p3/2 high-resolution spectrum. 


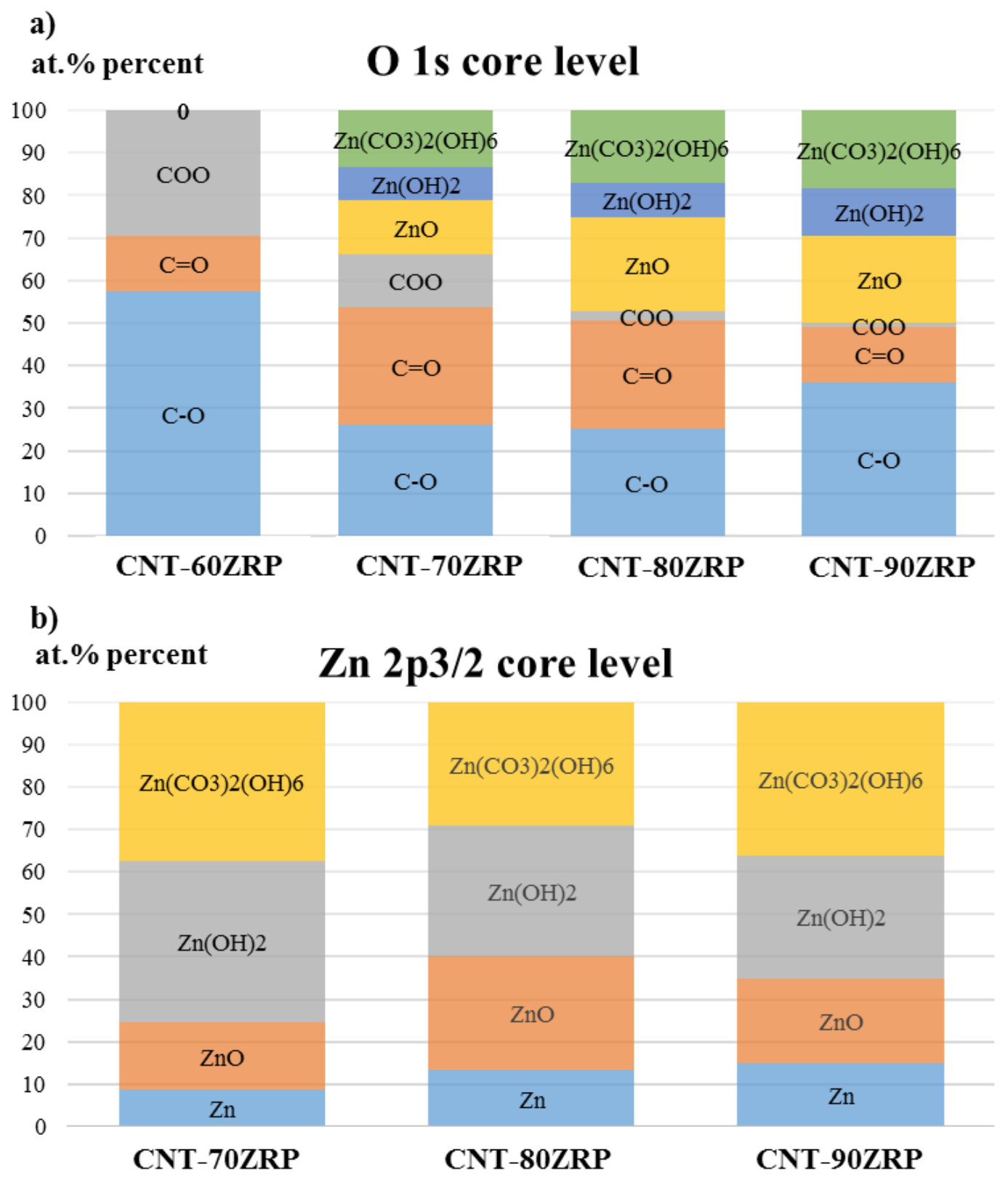

Fig. 18. Chemical compositions for the different CNT-ZRP formulations based on highresolution spectra for a) $\mathrm{O} 1 \mathrm{~s}$, and b) $\mathrm{Zn} 2 \mathrm{p} 3 / 2$. 
Table 1. Chemical composition of simulated concrete pore (SCP) solution in presence of chloride ions.*

\begin{tabular}{llllc}
\hline & {$[\mathrm{KOH}]$} & {$[\mathrm{NaOH}]$} & {$\left[\mathrm{Ca}(\mathrm{OH})_{2}\right]$} & {$[\mathrm{NaCl}]$} \\
\hline Molarity $(\mathrm{M})$ & 0.08 & 0.02 & 0.001 & 0.1 \\
\hline
\end{tabular}

* The chemical composition of the simulated concrete pore solution provides a chloride to hydroxide ratio of 1 . 
Table 2. Specifications of the different coating systems.

\begin{tabular}{ccccc}
\hline Coating & $\begin{array}{c}\text { Zinc } \\
(\mathrm{wt} \%)\end{array}$ & $\begin{array}{c}\text { Tesla P1150ASAS } \\
(\text { Carbon nanotubes }<1 \%) \\
(\mathrm{wt} \%)\end{array}$ & $\begin{array}{c}\text { Tesla P1150BSAS } \\
(\mathrm{wt} \%)\end{array}$ & $\begin{array}{c}\text { Dry film thickness } \\
(\mu \mathrm{m})\end{array}$ \\
\hline CNT-60ZRP & 60 & 26.7 & 13.3 & $101.6 \pm 18.2$ \\
CNT-70ZRP & 70 & 20.0 & 10.0 & $101.6 \pm 10.6$ \\
CNT-80ZRP & 80 & 13.4 & 6.6 & $101.6 \pm 14.2$ \\
CNT-90ZRP & 90 & 6.7 & 3.3 & $101.6 \pm 6.6$ \\
\hline
\end{tabular}


Table 3. EDS results (Atomic Percent) at indicated locations in SEM images of different CNTZRP systems immersed in the SCP solution.

\begin{tabular}{ccccccccc}
\hline Coating & Day & Region & $\mathrm{Zn}$ & $\mathrm{Fe}$ & $\mathrm{O}$ & $\mathrm{Cl}$ & $\mathrm{Na}$ & $\mathrm{Ca}$ \\
\hline CNT-60ZRP & 90 & 1 & 1.15 & - & 74.52 & 0.28 & 1.12 & 22.62 \\
& & 1 & 15.53 & 0.79 & 61.74 & 0.22 & 21.23 & 0.04 \\
CNT-70ZRP & 90 & 2 & 37.31 & - & 46.90 & 8.34 & 7.42 & 0.03 \\
& & 3 & 29.70 & - & 52.43 & 0.54 & 15.90 & 0.00 \\
CNT free-70ZRP & 90 & 1 & 3.21 & - & 71.39 & 1.21 & 6.68 & 16.39 \\
& & 2 & 4.77 & 76.27 & 12.48 & 2.10 & 3.77 & 0.17 \\
& & 1 & 64.91 & - & 10.1 & 0.79 & 24.15 & 0 \\
CNT-80ZRP & & 2 & 31.19 & - & 42.32 & 8.89 & 17.51 & 0.09 \\
& 90 & 3 & 28.59 & - & 54.37 & 1.97 & 13.71 & 1.15 \\
& & 4 & 30.27 & - & 59.91 & 0.53 & 8.26 & 0.48 \\
& & 5 & 37.02 & - & 42.62 & 0.45 & 18.04 & 0.66 \\
\hline
\end{tabular}


Table 4. Chemical compositions for the different CNT-ZRPs based on high-resolution spectra for $\mathrm{C} 1 \mathrm{~s}, \mathrm{O} 1 \mathrm{~s}$, and $\mathrm{Zn} 2 \mathrm{p} 3 / 2$.

\begin{tabular}{|c|c|c|c|c|c|c|c|c|c|c|}
\hline \multirow{3}{*}{$\begin{array}{l}\text { photoelectron } \\
\text { peak }\end{array}$} & \multirow{3}{*}{ Specie } & \multirow{3}{*}{$\begin{array}{l}\text { Binding } \\
\text { Energy }\end{array}$} & \multirow{2}{*}{\multicolumn{2}{|c|}{$\begin{array}{c}\text { CNT-60ZRP } \\
\text { Atomic } \\
\text { composition }(\%)\end{array}$}} & \multirow{2}{*}{\multicolumn{2}{|c|}{$\begin{array}{c}\text { CNT-70ZRP } \\
\text { Atomic } \\
\text { composition }(\%)\end{array}$}} & \multirow{2}{*}{\multicolumn{2}{|c|}{$\begin{array}{c}\text { CNT-80ZRP } \\
\text { Atomic } \\
\text { composition }(\%)\end{array}$}} & \multirow{2}{*}{\multicolumn{2}{|c|}{$\begin{array}{c}\text { CNT-90ZRP } \\
\text { Atomic } \\
\text { composition }(\%)\end{array}$}} \\
\hline & & & & & & & & & & \\
\hline & & & $\begin{array}{c}\text { Intact } \\
\text { coating }\end{array}$ & $\begin{array}{c}\text { Exposed } \\
\text { coating }\end{array}$ & $\begin{array}{l}\text { Intact } \\
\text { coating }\end{array}$ & $\begin{array}{c}\text { Exposed } \\
\text { coating }\end{array}$ & $\begin{array}{l}\text { Intact } \\
\text { coating }\end{array}$ & $\begin{array}{c}\text { Exposed } \\
\text { coating }\end{array}$ & $\begin{array}{l}\text { Intact } \\
\text { coating }\end{array}$ & $\begin{array}{c}\text { Exposed } \\
\text { coating }\end{array}$ \\
\hline \multirow{5}{*}{$\mathrm{C} 1 \mathrm{~s}$} & $\mathrm{C}-\mathrm{C} / \mathrm{C}-\mathrm{H}$ & 285 & 76.67 & 37.02 & 69.76 & 33.80 & 76.88 & 34.6 & 24.48 & 19.87 \\
\hline & $\mathrm{C}-\mathrm{O}$ & 286.5 & 16.55 & 39.24 & 23.89 & 37.18 & 17.21 & 10.22 & 31.59 & 23.78 \\
\hline & $\mathrm{C}=\mathrm{O}$ & 287.91 & 6.78 & 18.27 & 6.35 & 17.60 & 5.91 & 18.18 & 27.97 & 29.94 \\
\hline & $\mathrm{COO}$ & 288.8 & & 5.46 & & 8.77 & & 21.39 & 15.96 & 19.41 \\
\hline & $\mathrm{Zn}(\mathrm{CO}) 3(\mathrm{OH}) 6$ & 290.97 & & & & 2.66 & & 15.62 & & 6.99 \\
\hline \multirow{6}{*}{ O 1s } & $\mathrm{C}-\mathrm{O}$ & 533.34 & 63.6 & 57.41 & 67.88 & 25.94 & 63.99 & 25.24 & 67.32 & 36.17 \\
\hline & $\mathrm{C}=\mathrm{O}$ & 534.77 & 36.4 & 13.01 & 32.12 & 27.87 & 36.01 & 25.31 & 32.67 & 12.96 \\
\hline & $\mathrm{COO}$ & 532 & & 29.58 & & 12.34 & & 2.29 & & 0.92 \\
\hline & $\mathrm{ZnO}$ & 529.92 & & & & 12.66 & & 21.95 & & 20.48 \\
\hline & $\mathrm{Zn}(\mathrm{OH}) 2$ & 531.7 & & & & 7.83 & & 8.19 & & 11.17 \\
\hline & $\mathrm{Zn}(\mathrm{CO}) 3(\mathrm{OH}) 6$ & 531.4 & & & & 13.36 & & 7.62 & & 18.30 \\
\hline \multirow{4}{*}{$\mathrm{Zn} 2 \mathrm{p} 3 / 2$} & $\mathrm{Zn}$ & 1019.3 & & & & 8.53 & & 13.39 & & 14.89 \\
\hline & $\mathrm{ZnO}$ & 1020.1 & & & & 16.03 & & 26.65 & & 20.07 \\
\hline & $\mathrm{Zn}(\mathrm{OH}) 2$ & 1023.9 & & & & 38.03 & & 30.84 & & 28.94 \\
\hline & $\mathrm{Zn}(\mathrm{CO}) 3(\mathrm{OH}) 6$ & 1022.04 & & & & 37.41 & & 17.01 & & 36.09 \\
\hline
\end{tabular}

